\title{
155Gd Mössbauer Spectroscopy on Intermetallics - An Overview
}

\begin{tabular}{|r|l|}
\hline Journal: & Zeitschrift für Anorganische und Allgemeine Chemie \\
\hline Manuscript ID: & zaac. 201000171.R1 \\
\hline Wiley - Manuscript type: & Research Report \\
\hline Date Submitted by the \\
Author: & 01-Jul-2010 \\
\hline Complete List of Authors: & $\begin{array}{l}\text { Poettgen, Rainer; Westf. Wilhelms-Universitaet, Inst. f. Anorgan. u. } \\
\text { Analyt. Chemie } \\
\text { Latka, Kazimierz }\end{array}$ \\
\hline Keywords: & gadolinium, Mössbauer spectroscopy \\
\hline
\end{tabular}

\section{S) ScholaroNE" \\ Manuscript Central}




\title{
${ }^{155}$ Gd Mössbauer Spectroscopy on Intermetallics - An Overview
}

\author{
Rainer Pöttgen, ${ }^{*[a]}$ and Kazimierz Lątka ${ }^{[b]}$
}

Received,

Running title: ${ }^{155} \mathrm{Gd}$ Mössbauer Spectroscopy

Keywords: $\quad{ }^{155} \mathrm{Gd}$ Mössbauer Spectroscopy; Intermetallic Compounds

\begin{abstract}
Gd}$ Mössbauer spectroscopy on intermetallic compounds is a useful complementary spectroscopic tool for the determination of magnetic structures, since the high absorption cross-section strongly hampers neutron diffraction experiments for compounds containing natural gadolinium. The recent trends applied to solid state chemistry and materials sciences for that spectroscopic technique are reviewed.
\end{abstract}

* Prof. Dr. Rainer Pöttgen

Fax: +49-251-8336002

E-mail: pottgen@uni-muenster.de

[a] Institut für Anorganische und Analytische Chemie, Universität Münster Corrensstrasse 30, 48149 Münster, Germany

[b] Marian Smoluchowski Institute of Physics, Jagiellonian University, Reymonta 4, 30-059 Kraków, Poland

\section{Introduction}

The half-filled $4 f$ shell leads to remarkable magnetic properties for the rare earth metal gadolinium. It has a quite high paramagnetic moment of $7.94 \mu_{\mathrm{B}} / \mathrm{Gd}$ atom and has been described as a ferromagnet [1]. The complex temperature dependence of its magnetic structure, however, has been controversially discussed since the early description [2]. New investigations on high-purity gadolinium crystals [3] confirm ferromagnetic 
ordering between the spin-reorientation and the Curie temperature and weaken hints for helical antiferromagnetic ordering. This basic knowledge on the magnetic ground state of gadolinium strongly underlines the necessity for basic research. The spin reorientation around $260 \mathrm{~K}$, however, is not detectable via ${ }^{155} \mathrm{Gd}$ Mössbauer spectroscopy due to the vanishing f-factor at higher temperature.

The Curie temperature of gadolinium amounts to 294(1) K [4]. The accompanied phase transition to a paramagnetic state has large importance for magnetic cooling, respectively heating near room temperature, an important technological aspect. Determination of the magnetocaloric effect shows that the purity of the sample is essential for determination of the intrinsic properties.

Ingoing from elemental gadolinium, a variety of binary and ternary intermetallic gadolinium compounds has been synthesized and characterized with respect to their magnetocaloric properties, in order to transfer these properties to new compounds for modulating application oriented properties. Recent results confirm this hope. To give an example, $\mathrm{Gd}_{5} \mathrm{Si}_{2} \mathrm{Ge}_{2}$ [5] has a $30 \%$ higher adiabatic temperature with respect to elemental gadolinium. This important parameter of magnetocaloric properties of a given compound specifies the temperature change of the material upon an adiabatic change of the magnetic field. The extensive investigation of the giant magnetic caloric (GMC), giant magnetoresistance (GMR) or giant magnetostrictive (GMS) effects is a main field in current gadolinium-based research. Further examples are GdFeSi [6], $\operatorname{GdMg} X(X=\mathrm{Al}$, $\mathrm{Ga}, \mathrm{In}$ ) [7] or $\mathrm{GdFe}_{2}$ and $\mathrm{GdCo}_{2}$ [8], which have also been studied with respect to their magneto-optical properties. Some of the ternary compounds might be suitable for technical processes. Based on its magnetocaloric performance, ferromagnetic $\mathrm{GdNiGa}$ [9] is taken into consideration for magnetic cooling of hydrogen gas.

Although such gadolinium intermetallics show promising magnetocaloric properties, determination of their magnetic structure is not an easy task. With 49000 barns, gadolinium has the highest cross-section for thermal neutrons, drastically hampering classical neutron diffraction experiments. Besides magnetic measurements on oriented single crystals, ${ }^{155} \mathrm{Gd}$ Mössbauer spectroscopy is a useful complementary tool for elucidation of the magnetic structures. A concise overview on the theoretical background of ${ }^{155} \mathrm{Gd}$ Mössbauer spectroscopy can be found in a review article by Czjzek [10]. 
Within SPP 1166 Lanthanoidspezifische Funktionalitäten in Molekül und Material we have investigated the structures, magnetic properties and ${ }^{155} \mathrm{Gd}$ Mössbauer spectroscopic data of a variety of gadolinium intermetallics [11-23]. These results and parallel data from literature on intermetallic gadolinium compounds are reviewed herein. Some intermetallic compounds have already been included in the older review by Czjzek [10]. The latter review and an article by Silver and Withnall [24] give good literature overview on ${ }^{155} \mathrm{Gd}$ data of different gadolinium based oxides. Herein we have only considered literature later then 1993.

Our report is written from a synthetic solid state chemist's point of view. We do not go into physical details, but we use the information supplied by the ${ }^{155} \mathrm{Gd}$ spectra in order to better understand structure-property relationships.

\section{Experimental}

\section{Synthesis techniques}

The various $\mathrm{Gd}_{\mathrm{x}} T_{\mathrm{y}} X_{\mathrm{z}}$ intermetallics reviewed herein have all been prepared from the pure elements under suitable argon atmosphere in order to avoid side reactions with residual oxygen. Most compounds melt congruently and they have been obtained via arcmelting. This is especially possible if all three elements have comparable melting and boiling points. If elements with comparatively low boiling points, $e . g$. magnesium or cadmium, are used, arc-melting leads to large weight losses upon evaporation. In those cases the samples can be prepared by induction melting of the elements in sealed highmelting metal tubes. Mostly niobium and tantalum have been used as inert container material. The $X$ components $\mathrm{Ga}, \mathrm{Al}, \mathrm{In}$, and $\mathrm{Sn}$ have high liquidus ranges. This is an excellent prerequisite for metal flux growth techniques [25]. The low melting point of these elements enables, besides solubility of the reactants, low reaction temperatures, while the high boiling temperatures avoid evaporations. The largest advantage of the flux techniques is the availability of larger single crystals for property measurements. For the detailed synthesis conditions we refer to the original articles.

\section{The ${ }^{155}$ Gd Mössbauer Spectroscopic Source}

Gadolinium has several isotopes of which the Mössbauer effect has been observed for ${ }^{154} \mathrm{Gd},{ }^{155} \mathrm{Gd},{ }^{156} \mathrm{Gd},{ }^{157} \mathrm{Gd},{ }^{158} \mathrm{Gd}$, and ${ }^{160} \mathrm{Gd}$. For physical reasons, ${ }^{155} \mathrm{Gd}$ is the best 
choice for an extensive use (half-life (linewidth), transition energy, source half life etc.) [26]. The source isotope ${ }^{155} \mathrm{Eu}$, see Fig. 1, decays into three excited states of ${ }^{155} \mathrm{Gd}$ with Mössbauer transitions at 105, 86, and $60 \mathrm{keV}$. The $86.5 \mathrm{keV}$ gamma rays (Ig = 3/2, E1, $\mathrm{Ie}=5 / 2)$ are used for the present experiments. In natural gadolinium the abundance of ${ }^{155} \mathrm{Gd}$ is $14.8 \%$. The half-life of the source is 4.96 years. The sources used are composed of neutron-activated powders of $\mathrm{SmPd}_{3}$ enriched up to $90 \%$ with the ${ }^{154} \mathrm{Sm}$ isotope. For the ${ }^{155} \mathrm{Eu}: \mathrm{SmPd}_{3}$ sources lead foils of $0.9 \mathrm{~mm}$ thickness are applied as a critical absorber to suppress the intensity of the higher $105.3 \mathrm{keV}$ gamma ray transition. A $\mathrm{NaI}(\mathrm{Tl})$ scintillation counter or $\mathrm{Ge}(\mathrm{Li})$ semiconducting detector is used to measure the $86.5 \mathrm{keV}$ resonance transition gamma rays. The absorber thickness needs to be optimized due to high-energy elements of the gamma rays [27].

\section{Analyses of the Data}

For the proper description of the recorded ${ }^{155} \mathrm{Gd}$ Mössbauer spectra in the magnetically ordered state a least-squares fitting procedure which includes the diagonalization of the full hyperfine Hamiltonian within the transmission integral approximation is necessary [10]. The Hamiltonian written in the principal axes system of electric field gradient $(\mathrm{EFG})$ tensor is given by the formula [10]:

$$
\hat{H}=g \mu_{B} \mathrm{H}_{\mathrm{hf}}\left[\hat{\mathrm{I}}_{\mathrm{z}} \cos \theta+\frac{1}{2}\left(\hat{\mathrm{I}}_{+} e^{i \varphi}+\hat{\mathrm{I}}_{-} e^{i \varphi}\right) \sin \theta\right]+\frac{\Delta \mathrm{E}_{\mathrm{Q}}}{4 \mathrm{I}(2 \mathrm{I}-1)}\left[3 \hat{\mathrm{I}}_{\mathrm{z}}^{2} \hat{\mathrm{I}}^{2}+\frac{\eta}{2}\left(\hat{\mathrm{I}}_{+}^{2}+\hat{\mathrm{I}}_{-}^{2}\right)\right]
$$

The numerical diagonalization of this Hamiltonian gives eigenvalues and eigenvectors wherefrom the energies of the individual line positions and the relative line intensities can be calculated, respectively (see [10] and references therein).

As a result of least-squares fits to the experimental spectra the following parameters can be derived: the isomer shift $\delta_{\mathrm{IS}}$; the quadrupole interaction constant $\Delta E_{Q}=e Q_{g} V_{z z}$, where $Q_{g}=(1.30 \pm 0.02) \mathrm{b}$ [28], the magnetic hyperfine field $H_{h f}$, the asymmetry parameter $\eta=\left(V_{x x}-V_{y y}\right) / V_{z z}$, and the polar angles $\theta$ and $\varphi$ giving the direction of the magnetic hyperfine field with respect to the principal axes of the electric field gradient (EFG) tensor. If the direction of the magnetic hyperfine field follows the magnetic moment well then the polar angles $\theta$ and $\varphi$ contribute to our knowledge concerning realized magnetic ordering. 
It has to be emphasized that from a spectrum obtained in the paramagnetic state only the effective absolute quadrupole interaction value $\Delta E_{Q}^{e f f}=\left|e Q_{g} V_{z z}\right| \cdot\left(1+\eta^{2} / 3\right)^{1 / 2}$ can be inferred, because of the small magnitude of the excited quadrupole moment $Q_{e x}[10]$. In contrast, magnetic hyperfine split spectra have to be fitted with independent $\Delta E_{Q}=e Q_{g}$ $V_{z z}$ and $\eta$ parameters in a self-consistent way since they are usually correlated. It has to be stressed, here, that it is a common practise to keep the absolute value of $\Delta E_{Q}$ as equal to $\Delta E_{Q}^{\text {eff }}$ when fitting the magnetically split spectra since the values of $\Delta \mathrm{E}_{\mathrm{Q}}, \eta, \theta$ and $\varphi$ are usually strongly correlated in a magnetic region and they can not be determined independently for this case. However, this procedure can lead, when $\eta \neq 0$, to a remarkable higher $V_{z z}$ value.

For our own measurements, the source width $\Gamma_{\mathrm{S}}$ of the recoil-free emitted gamma line and the background reduced Debye-Waller factor of the source, $f_{\mathrm{S}}$, was determined from an independent measurement with a standard $\mathrm{GdFe}_{2}$ absorber and kept constant during the fits to the experimental spectra while the nuclear g-factor ratio, $g_{e x} / g_{g}$ and the ratio of nuclear quadrupole moments, $\mathrm{Q}_{\mathrm{ex}} / \mathrm{Q}_{\mathrm{g}}$ were constrained to 1.235 and 0.087 [29], respectively. The interference $\xi$-factor for the E1 transition of $86.5 \mathrm{keV}$ was fixed to the value $\xi=0.0275[30]$ in the absorption cross-section.

The ${ }^{155} \mathrm{Gd}$ Mössbauer spectroscopic data can be systemized in several ways [31]. An interesting approach was performed by de Vries et al. who interpreted data in terms of the model of Miedema and van der Woude [32]. Besides normal pressure data, ${ }^{155} \mathrm{Gd}$ Mössbauer spectroscopy under pressure is an interesting tool. Elemental gadolinium has been investigated up to $17 \mathrm{GPa}$ [33]. Such data are especially interesting, since the comparison of ${ }^{155} \mathrm{Gd}$ and ${ }^{151} \mathrm{Eu}$ Mössbauer spectroscopic measurements gives valuable information about the stability of $\mathrm{Eu}^{\mathrm{II}}$ under pressure. An extensive high-pressure ${ }^{155} \mathrm{Gd}$ Mössbauer spectroscopic study was also performed for $\mathrm{GdCo}_{5}, \mathrm{GdRu}_{2} \mathrm{Si}_{2}$, and $\mathrm{Gd}_{2} \mathrm{Fe}_{17} \mathrm{~N}_{3}$ [34], and the extensive results have been discussed in comparison to the high-pressure data of gadolinium metal. 


\section{Selected Intermetallic Compounds}

In the following chapters, the intermetallic gadolinium compounds are discussed in groups, depending on their structure types. The basic ${ }^{155} \mathrm{Gd}$ Mössbauer spectroscopic data (isomer shift, electric quadrupole splitting parameter, magnetic hyperfine field) are listed in Table 1.

\section{Equiatomic Compounds with AlB ${ }_{2}$-Related Structures}

The stannide GdAuSn has repeatedly been studied by ${ }^{155} \mathrm{Gd}$ Mössbauer spectroscopy [35-37]. GdAuSn crystallizes with the NdPtSb type structure, space group $P 6_{3} m c$, an ordered version of $\mathrm{AlB}_{2}$. Each gadolinium atom is surrounded by two puckered $\mathrm{Au}_{3} \mathrm{Sn}_{3}$ hexagons. For crystal chemical details of $\mathrm{AlB}_{2}$ related superstructures we refer to a review article [38]. The antiferromagnetic ordering in $\mathrm{GdAuSn}$ is paralleled by magnetic hyperfine field splitting in the ${ }^{155} \mathrm{Gd}$ spectrum. Data taken down to $4.2 \mathrm{~K}$ show approximately a Brillouin function. The $\mathrm{Au}-\mathrm{Sn}$ ordering has an influence also on the magnetic homogeneity of the samples, as discussed in [35-37].

GdCuSn [35] with the same structure type shows a significantly higher quadrupole splitting parameter (Table 1), indicating lower site symmetry (stronger structural distortion) for the gadolinium atoms as compared to the gold compound. Isotypic GdAuGe [11] has an almost equal isomer shift, indicating similar electron density at the gadolinium nuclei. The highest transferred hyperfine field of $4.87 \mathrm{~T}$, as observed by ${ }^{119} \mathrm{Sn}$ Mössbauer spectroscopy, occurs for GdAgSn [39], although an even higher field occurs in the structurally related Zintl phase EuZnSn (12.8 T) [40].

$\mathrm{GdAu}_{0.44} \mathrm{In}_{1.56}[11]$ shows a statistical occupancy of the gold and indium atoms on the hexagonal network. This has a peculiar effect on the temperature dependence of the magnetic hyperfine field. One does not observe a Brillouin function. The hyperfine field decreases in an almost linear fashion with increasing temperature with a hyperfine field of $19.8 \mathrm{~T}$ at $4.2 \mathrm{~K}$. This unusual behavior had been ascribed to a percolative demagnetization process with a coexistence of magnetically ordered and disordered (or differently ordered) domains.

The stannide GdNiSn [41] with the orthorhombic TiNiSi type structure shows much stronger distortion of the gadolinium coordination sphere as the hexagonal $\mathrm{AlB}_{2}$ super- 
structures. This low site symmetry is reflected in enhanced electric quadrupole splitting of $1.81 \mathrm{~mm} / \mathrm{s}$. Thus, the $30 \mathrm{~K}$ spectrum of GdNiSn shows a well resolved doublet. The ${ }^{155} \mathrm{Gd}$ spectrum in the magnetically ordered state led to two plausible models for the magnetic structure of GdNiSn. Either the magnetic moments are all collinear and lie in the $a b$-plane (or $\boldsymbol{c} b$-plane) or non-collinear and deviate from the crystallographic $b$ axis by $54(2)^{\circ}$. In this case the spectroscopic data helped to get an idea of the magnetic structure. Quite well resolved ${ }^{155} \mathrm{Gd}$ spectra were also obtained for a $\mathrm{Gd}_{0.1} \mathrm{~Tb}_{0.9} \mathrm{NiSn}$ sample (Figure 2). Doping with $10 \%$ gadolinium is sufficient to get a good signal-to-noise ratio.

Also for $\mathrm{Gd}_{2} \mathrm{PdSi}_{3}$ [42] the ${ }^{155} \mathrm{Gd}$ data underlined the magnetic susceptibility and resistivity results. However, the Mössbauer spectroscopic data have only been published graphically. In the magnetically ordered state the gadolinium atoms exhibit a huge hyperfine field larger than $30 \mathrm{~T}$ and one observes an abrupt jump in the temperature dependence of the hyperfine field near $15 \mathrm{~K}$, related to the magnetic ordering of one of the two crystallographically inequivalent gadolinium sites.

$\mathrm{Gd}_{2} \mathrm{RhSi}_{3}$ [43] crystallizes with an ordering variant of $\mathrm{AlB}_{2}$ with two crystallographically independent gadolinium sites. One gadolinium site has $12 \mathrm{Si}$ neighbors, while the other has $6 \mathrm{Si}+6 \mathrm{Rh}$ neighbors, resulting in drastically different crystal field interactions. Most likely the mixing of gadolinium $5 d$, $6 p$ states with the $\mathrm{Rh} 4 d$ states is responsible for the prevailing $5 d, 6 p$ electron asphericity and thus the enhanced quadrupole splitting parameter.

$\operatorname{GdCuSi}\left(\mathrm{T}_{\mathrm{N}}=14 \mathrm{~K}\right), \operatorname{GdCuGe}\left(\mathrm{T}_{\mathrm{N}}=19 \mathrm{~K}\right)$, and $\mathrm{GdGaAl}\left(\mathrm{T}_{\mathrm{N}}=50 \mathrm{~K}\right)[44]$ crystallize with $\mathrm{AlB}_{2}$ subcells [38]. At least for $\mathrm{GdCuGe}$ [45], weak superstructure reflections (single crystal data) reveal the $\mathrm{Cu} / \mathrm{Ge}$ ordering in a NdPtSb type fashion. Among the three compounds GdGaAl has the smallest $c / a$ ratio of the unit cell parameters. This is reflected in the highest quadrupole splitting parameter (Table 1). In a parallel work Mulder et al. investigated the ${ }^{155} \mathrm{Gd}$ Mössbauer spectra of the whole $\mathrm{AlB}_{2}$ type solid solution $\mathrm{GdGa}_{2-\mathrm{x}} \mathrm{Al}_{\mathrm{x}}$ [46]. As a result of the changing $c / a$ ratio within the solid solution the quadrupole splitting parameter changes from positive to negative for $\mathrm{x}>0.5$ in $\mathrm{GdGa}_{2-\mathrm{x}} \mathrm{Al}_{\mathrm{x}}$. At $4.2 \mathrm{~K}$, the isomer shifts decrease from $0.59 \mathrm{~mm} / \mathrm{s}$ for $\mathrm{x}=0$ to $0.51 \mathrm{~mm} / \mathrm{s}$ for $\mathrm{x}=1.20$. 
Similar trend is observed for the hyperfine field $(33.3 \rightarrow 25.7 \mathrm{~T})$, however, the $\mathrm{x}=0.75$ sample showed $34.9 \mathrm{~T}$.

The antimonides GdNiSb and GdPdSb both crystallize with the cubic MgAgAs and the hexagonal NdPtSb type structure, respectively. These structures just differ in the stacking sequence of the $\mathrm{Ni}_{3} \mathrm{Sb}_{3}$, respectively $\mathrm{Pd}_{3} \mathrm{Sb}_{3}$ hexagons, i. e. ABC for the $\mathrm{MgA}-$ gAs and $\mathrm{AB}$ for the NdPtSb type. The spectroscopically derived parameters [47] are comparable to the structurally related stannides (Table 1). GdNiSb, however, shows an $\mathrm{AlB}_{2}$ related high-temperature modification. The higher quadrupole splitting parameter and the smaller hyperfine field are indicative for substantial structural disorder $(\mathrm{Ni}-\mathrm{Sb}$ mixing) with respect to the cubic low-temperature phase.

\section{Equiatomic Compounds with ZrNiAl Structure}

GdAgGe crystallizes with the hexagonal $\mathrm{ZrNiAl}$ type structure [11]. The gadolinium atoms have significantly lower site symmetry as compared to the $\mathrm{AlB}_{2}$ related materials discussed above. This is reflected in a much larger quadrupole splitting parameter. Similar to GdAuGe, and isotypic GdAuIn, the temperature dependence of the magnetic hyperfine field nicely follows a Brillouin function with $S=7 / 2$ behavior (Figure 3). A significant difference of equiatomic GdAuIn with respect to $\mathrm{GdAu}_{0.44} \operatorname{In}_{1.56}$ (vide ultra) concerns the isomer shift, i. e. $0.452 \mathrm{~mm} / \mathrm{s}$ for $\mathrm{GdAu}_{0.44} \mathrm{In}_{1.56}$ vs. 0.355 for GdAuIn, indicating a higher electron density at the gadolinium nuclei in GdAuIn.

$\operatorname{GdPdMg}\left(\mathrm{T}_{\mathrm{C}}=95.7 \mathrm{~K}\right), \operatorname{GdAgMg}\left(\mathrm{T}_{\mathrm{C}}=39.3 \mathrm{~K}\right), \operatorname{GdPtMg}\left(\mathrm{T}_{\mathrm{C}}=97.6 \mathrm{~K}\right)[14]$, $\operatorname{GdAuMg}\left(\mathrm{T}_{\mathrm{N}}=81.1 \mathrm{~K}\right)[15], \operatorname{GdPdCd}\left(\mathrm{T}_{\mathrm{C}}=62.5 \mathrm{~K}\right)[13]$, and $\operatorname{GdAuCd}\left(\mathrm{T}_{\mathrm{N}}=66.5 \mathrm{~K}\right)$ [16] show all comparatively high magnetic ordering temperatures, accompanied by substantial magnetic hyperfine field splitting in the $4.2 \mathrm{~K}{ }^{155} \mathrm{Gd}$ spectra. Among the many equiatomic compounds investigated (Table 1), those with magnesium and cadmium shows the smallest isomer shifts. These trends are discussed in detail below. The quadrupole splitting parameter of these compounds shows also significant differences. In that series of compounds, with increasing valence electron concentration, the $c / a$ ratio of the cell increases which is paralleled by an increase of $\Delta E_{Q}$. Thus, the structural distortion is readily expressed in the ${ }^{155} \mathrm{Gd}$ spectra. The spectroscopic data of GdAuCd [16] in com- 
bination with susceptibility measurements point to a propagation vector $\mathbf{k}=(1 / 2,0$, $1 / 2)$.

\section{Equiatomic Compounds with CeFeSi Type}

The silicides GdMnSi, GdFeSi, and GdCoSi [48] adopt the tetragonal CeFeSi type structure, space group $P 4 / n m m$, a ternary ordered version of $\mathrm{La}_{2} \mathrm{Sb}$. The three compounds have almost similar isomer shift values (Table 1), but the electric quadrupole parameters increase with increasing electron count. Such a behavior might be explained in terms of a decreasing hybridization of the gadolinium valence states with the transition metal $3 d$ states. The magnetic hyperfine field increases in the same sequence and can be interpreted as a decreasing contribution of the conduction electron in the sequence $\mathrm{Mn} \rightarrow \mathrm{Fe} \rightarrow \mathrm{Co}$.

\section{$\mathrm{ThCr}_{2} \mathrm{Si}_{2}$ Type and Related Compounds}

The whole series of $\mathrm{Gd}_{2} \mathrm{Ge}_{2}$ germanides ( $T=\mathrm{Mn}, \mathrm{Fe}, \mathrm{Co}, \mathrm{Ni}, \mathrm{Cu}, \mathrm{Ru}, \mathrm{Rh}, \mathrm{Pd}, \mathrm{Ag}$ ) with the tetragonal $\mathrm{ThCr}_{2} \mathrm{Si}_{2}$ type structure has been studied by temperature dependent ${ }^{155}$ Gd Mössbauer spectroscopy [49]. The diverse parameters are listed in Table 1. This extensive study nicely demonstrated that the sign of the $V_{z z}$ parameter derived from the quadrupole splitting helps to predict the magnetic macroscopic anisotropy behavior of the gadolinium atoms. For the $\mathrm{Gd}_{2} \mathrm{Ge}_{2}$ series a nice correlation between the difference between the average charge densities $\Delta \mathrm{n}_{\mathrm{WS}}=\mathrm{n}_{\mathrm{WS}}(T)-\mathrm{n}_{\mathrm{WS}}(\mathrm{Ge})$ at the edge of the atomic shells and the $V_{\mathrm{zz}}$ values is observed (Figure 4). Indeed, this is a function of the valence electron concentration (VEC); increasing $V_{z z}$ values are observed for an increasing VEC.

The germanide $\mathrm{GdAl}_{2} \mathrm{Ge}_{2}$ with the hexagonal $\mathrm{CaAl}_{2} \mathrm{Si}_{2}$ type structure $[43,50]$ has quite high site symmetry for the gadolinium atoms. No quadrupole splitting was needed for fitting the ${ }^{155} \mathrm{Gd}$ spectrum. In agreement with the general trends (vide infra), $\mathrm{GdAl}_{2} \mathrm{Ge}_{2}$ shows a comparatively high isomer shift of $0.57 \mathrm{~mm} / \mathrm{s}$. In agreement with the antiferromagnetic ordering at $19.7 \mathrm{~K} \mathrm{GdAl}_{2} \mathrm{Ge}_{2}$ shows full magnetic hyperfine field splitting with $H_{h f}=26.9 \mathrm{~T}$.

Further $\mathrm{ThCr}_{2} \mathrm{Si}_{2}$ type compounds studied by ${ }^{155} \mathrm{Gd}$ Mössbauer spectroscopy are $\mathrm{GdNi}_{2} \mathrm{Sb}_{2}\left(\mathrm{~T}_{\mathrm{N}}=6.5 \mathrm{~K}\right), \mathrm{GdCu}_{2} \mathrm{Sb}_{2}\left(\mathrm{~T}_{\mathrm{N}}=15.8 \mathrm{~K}\right)$, and $\mathrm{GdGa}_{2} \mathrm{Al}_{2}\left(\mathrm{~T}_{\mathrm{N}}=42.4 \mathrm{~K}\right)[51]$. The three compounds show full magnetic hyperfine field splitting in the magnetically 
ordered regime. The sign and value of the $V_{z z}$ parameters again scales with the VEC as discussed above.

$\mathrm{BaNiSn}_{3}$ type $\mathrm{GdIrSi}_{3}$ [52] can be considered as a non-centrosymmetric occupancy variant of the $\mathrm{ThCr}_{2} \mathrm{Si}_{2}$ family [53]. In contrast to the $81 \mathrm{~K}$ antiferromagnet $\mathrm{GdIr}_{2} \mathrm{Si}_{2}$ with $\mathrm{ThCr}_{2} \mathrm{Si}_{2}$ type, $\mathrm{GdIrSi}_{3}$ shows a much lower Néel temperature of $15.5 \mathrm{~K}$. This might be a consequence of the non-centrosymmetric iridium-silicon coordination around the gadolinium atoms. The higher silicon content in $\mathrm{GdIrSi} i_{3}$ with respect to $\mathrm{GdIr}_{2} \mathrm{Si}_{2}$ is reflected in a much higher isomer shift, i. e. 0.640 vs. $0.533 \mathrm{~mm} / \mathrm{s}$. The lower site symmetry leads to a higher quadrupole splitting parameter for $\mathrm{GdIrSi}_{3}$.

Further $\mathrm{BaNiSn}_{3}$ type gadolinium intermetallics have been studied [54]. The ${ }^{155} \mathrm{Gd}$ Mössbauer spectroscopic data are listed in Table 1. The four compounds $\mathrm{GdCoSi}_{3}\left(\mathrm{~T}_{\mathrm{N}}=\right.$ $9.6 \mathrm{~K}), \operatorname{GdNiGa}_{3}\left(\mathrm{~T}_{\mathrm{N}}=14.5 \mathrm{~K}\right), \mathrm{GdCuGa}_{3}\left(\mathrm{~T}_{\mathrm{N}}=10.1 \mathrm{~K}\right)$, and $\mathrm{GdCuAl}_{3}\left(\mathrm{~T}_{\mathrm{N}}=10 \mathrm{~K}\right)$ all show magnetic hyperfine field splitting at $4.2 \mathrm{~K}$, in full agreement with the susceptibility measurements. The most interesting sample in this series of four compounds is $\mathrm{GdCuAl}_{3}$. Its ${ }^{155} \mathrm{Gd}$ Mössbauer spectrum at $4.2 \mathrm{~K}$ was well reproduced with three spectral components at the same isomer shift, but with distinctly different magnetic hyperfine fields. This is certainly a consequence of structural disorder, indicating different domains with varying magnetic long-range ordering. The course of the isomer shifts as a function of the $p$-element content and the VEC is discussed below.

\section{Borides, Carbides, and Borocarbides}

The rhodium-rich borides $\mathrm{GdRh}_{3} \mathrm{~B}$ and $\mathrm{GdRh}_{3} \mathrm{~B}_{0.706}$ have been studied by ${ }^{155} \mathrm{Gd}$ Mössbauer spectroscopy at $12 \mathrm{~K}$ [55], resulting in isomer shifts of 0.11 and $0.08 \mathrm{~mm} / \mathrm{s}$, respectively. The decrease in boron concentration is directly reflected in a decrease of the isomer shift. This is consistent with a slightly larger $s$ electron density at the gadolinium nuclei.

Antiferromagnetic ordering has been observed for the complex carbides $\mathrm{GdCoC}_{2}\left(\mathrm{~T}_{\mathrm{N}}\right.$ $15.6 \mathrm{~K})$ and $\mathrm{GdNiC}_{2}\left(\mathrm{~T}_{\mathrm{N}}=20.0 \mathrm{~K}\right)[56,57]$. In agreement with the full magnetic saturation observed in the magnetization experiments, both samples showed substantial magnetic hyperfine field splitting at $4.2 \mathrm{~K}$ (Table 1 ). The ${ }^{155} \mathrm{Gd}$ data allowed for a determi- 
nation of the crystal field parameters of $\mathrm{A}^{0}{ }_{2}=-498$ and $277 \mathrm{~K} / \mathrm{a}^{2}{ }_{0}$ for $\mathrm{GdCoC}_{2}$ and $\mathrm{GdNiC}_{2}$, respectively.

A complex magnetic behavior has been observed for the silicide carbide $\mathrm{GdRu}_{2} \mathrm{SiC}$ [21]. This $\mathrm{DyFe}_{2} \mathrm{SiC}$ type compound orders antiferromagnetically at $10 \mathrm{~K}$ shows an $\mathrm{S}=$ $7 / 2$ Brillouin type increase of the magnetic hyperfine field with decreasing temperature, leading to a saturation value of $30.4 \mathrm{~T}$. Below $4.2 \mathrm{~K}$ one observes a drastic change of the magnetic structure. The ${ }^{155} \mathrm{Gd}$ Mössbauer spectrum shows a complex field distribution with five maxima (Figure 5), indicating a non-collinear magnetic structure.

The borocarbides $\mathrm{GdCo}_{2} \mathrm{~B}_{2} \mathrm{C}$ and $\mathrm{GdNi}_{2} \mathrm{~B}_{2} \mathrm{C}[58,59]$ order magnetically below 21 and $5.5 \mathrm{~K}$, respectively. The ordering temperatures have been determined from the temperature dependence of the magnetic hyperfine field at the gadolinium nuclei. Quantitative evaluation of the quadrupole splitting parameters led to an estimate of the secondorder crystal field parameters $\mathrm{A}_{2}^{0}=-428$ and $-346 \mathrm{~K} / \mathrm{a}_{0}^{2}$ for $\mathrm{GdNi}_{2} \mathrm{~B}_{2} \mathrm{C}$ and $\mathrm{GdCo}_{2} \mathrm{~B}_{2} \mathrm{C}$, respectively. More detailed temperature dependent studies [59] then revealed a more complex magnetic ordering behavior. Below ca. $14 \mathrm{~K} \mathrm{GdNi}_{2} \mathrm{~B}_{2} \mathrm{C}$ shows a spiral-like magnetic structure with gadolinium magnetic moments rotating within the $b c$ plane. In the temperature range between $14 \mathrm{~K}$ and the Néel temperature (ca. $20 \mathrm{~K}$ ), the magnetic structure becomes a sine-modulated one with the gadolinium magnetic moments perpendicular to the tetragonal $c$ axis.

\section{Complex Silicides}

Ternary silicides and germanides $\mathrm{Gd}_{5} \mathrm{Si}_{2} \mathrm{Ge}_{2}$ have intensively been studied in the last 15 years with respect to their outstanding magnetocaloric properties. In a recent study the solid solution $\mathrm{Gd}_{5} \mathrm{Ge}_{2}\left(\mathrm{Si}_{1-\mathrm{x}} \mathrm{Sn}_{\mathrm{x}}\right)_{2}(\mathrm{x}=0.23$ and 0.40$)$ has been investigated with respect to ${ }^{155} \mathrm{Gd}$ Mössbauer spectroscopy [60]. The spectra showed two independent spectral contributions which correspond to the two crystallographically independent gadolinium sites. This is in agreement with the low-temperature structure determined from Xray powder diffraction.

$\mathrm{Gd}_{2} \mathrm{Fe}_{3} \mathrm{Si}_{5}$ contains one gadolinium site with site symmetry $m$ [61]. Consequently no axial symmetry is observed and the ${ }^{155} \mathrm{Gd}$ spectrum at $10 \mathrm{~K}$, slightly above the Néel temperature of $8.6 \mathrm{~K}$ shows substantial quadrupole splitting of $-3.3 \mathrm{~mm} / \mathrm{s}$. In the mag- 
netically ordered state (4.2 $\mathrm{K}$ data), $\mathrm{Gd}_{2} \mathrm{Fe}_{3} \mathrm{Si}_{5}$ shows full magnetic hyperfine field splitting with a refined hyperfine field of 26(3) $\mathrm{T}$.

\section{Complex Ternary Indium Compounds}

$\mathrm{Gd}_{4} \mathrm{Pd}_{10} \mathrm{In}_{21}$ [20] crystallizes with the monoclinic $\mathrm{Ho}_{4} \mathrm{Ni}_{10} \mathrm{Ga}_{21}$ type structure with two crystallographically independent gadolinium sites in the unit cell which can be resolved in the ${ }^{155} \mathrm{Gd}$ spectrum. At $20 \mathrm{~K}$, slightly above the Néel temperature of $14.2 \mathrm{~K}$, the spectrum could be well reproduced with two spectral components and the parameters listed in Table 1. In the magnetically ordered state a reliable fit to the experimental data was not possible. Nevertheless, the ${ }^{155} \mathrm{Gd}$ data clearly manifest the magnetic ordering of the gadolinium atoms.

Strong quadrupole splitting has also been observed for the $60.5 \mathrm{~K}$ ferromagnet LT$\mathrm{GdNiIn}_{2}\left(\mathrm{MgCuAl}_{2}\right.$ type $)$ [19]. The structure contains only one crystallographic gadolinium site with site symmetry $m 2 m$. The refined experimental line width of $0.61(4) \mathrm{mm} / \mathrm{s}$ is greater than the natural one, pointing to structural imperfections in the investigated sample. In the magnetically ordered state the spectrum is well described by a single magnetic component without any hyperfine field distribution. The resolution of the spectrum, however, did not allow for a determination of the magnetic structure of LTGdNiIn $_{2}$.

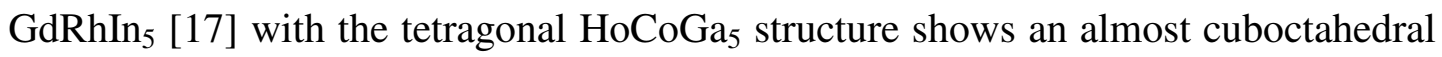
indium coordination for the gadolinium atoms. The tetragonal distortion is only very small, as is expressed by the small quadrupole splitting parameter of $0.171 \mathrm{~mm} / \mathrm{s}$. The high indium content leads to a very high isomer shift of $0.657 \mathrm{~mm} / \mathrm{s}$. This is discussed in the context with other gadolinium intermetallics in the last chapter. In the antiferromagnetic state $\mathrm{GdRhIn}{ }_{5}$ shows full hyperfine field splitting with $H_{h f}=23.3 \mathrm{~T}$. The magnetic and ${ }^{155} \mathrm{Gd}$ Mössbauer spectroscopic data point to a simple collinear antiferromagnetic structure with the gadolinium magnetic moments aligned in- or close to the basal plane. It was pointed out that the magnetic structure in this case could consist of ferromagnetic Gd planes perpendicular to the $c$-axis with a stacking sequence +-+- leading to the net antiferromagnetic ordering. 
$\mathrm{GdCu}_{5.1} \mathrm{In}_{6.9}$ is a ternary ordered version of the $\mathrm{ThMn}_{12}$ type [62]. Again, similar to $\mathrm{GdRhIn}_{5}$ discussed above, also $\mathrm{GdCu}_{5.1} \mathrm{In}_{6.9}$ shows a high isomer shift of $0.597 \mathrm{~mm} / \mathrm{s}$. The tetragonal distortion of the gadolinium coordination polyhedron leads to a quadrupole splitting parameter of $0.59 \mathrm{~mm} / \mathrm{s}$. $\mathrm{GdCu}_{5.1} \mathrm{In}_{6.9}$ is a $13.4 \mathrm{~K}$ antiferromagnet. Below the Néel temperature, the magnetic hyperfine field detected at the gadolinium nuclei continuously increase up to $25 \mathrm{~T}$ at $4.2 \mathrm{~K}$ as a $\mathrm{S}=7 / 2$ Brillouin function. The ${ }^{155} \mathrm{Gd}$ data point to an alignment of the gadolinium magnetic moments within the $a b$-plane.

The half-Heusler compound $\mathrm{GdCu}_{2} \mathrm{In}[63]$ is a $9.6 \mathrm{~K}$ antiferromagnet. Below the ordering temperature, the temperature dependence of the magnetic hyperfine field follows a $J=7 / 2$ Brillouin function. Based on these detailed temperature dependent investigations, the total contribution to the magnetic hyperfine field at the ${ }^{155} \mathrm{Gd}$ nuclei in gadolinium containing Heusler compounds resulting from the conduction electron polarisation is $+9.8(2.5) \mathrm{T}$.

$\mathrm{GdPt}_{4} \mathrm{In}$ [23] crystallizes with the cubic $\mathrm{MgCu}_{4} \mathrm{Sn}$ type structure and orders ferromagnetically at $\mathrm{T}_{\mathrm{C}}=21.9 \mathrm{~K}$. In agreement with the high platinum content, one observes a low isomer shift of $0.32 \mathrm{~mm} / \mathrm{s}$ at $4.2 \mathrm{~K}$. Although the structure is cubic, due to a small degree of Gd / In statistics, one observes electric quadrupole splitting of $1.28 \mathrm{~mm} / \mathrm{s}$. This structural disorder is also reflected in a lower hyperfine field of only $16.5 \mathrm{~T}$ at 4.2 T. Similar disorder has been observed for $\mathrm{GdCu}_{4} \mathrm{In}[64,65]$, however, the hyperfine field of $22 \mathrm{~T}$ is larger.

A peculiar compound is the icosahedral quasicrystal of composition $\operatorname{Gd}_{14} \mathrm{Ag}_{50} \operatorname{In}_{36}$ $[66,67]$. This quasicrystal is a spin-glass system. ${ }^{155} \mathrm{Gd}$ Mössbauer spectra show a distribution of electric quadrupole splitting, underlining the existence of a multiplicity of gadolinium sites. In the ${ }^{155} \mathrm{Gd}$ Mössbauer spectra magnetic hyperfine field splitting sets in at a temperature slightly higher than the freezing temperature. The spectra confirm that the gadolinium spins are frozen at $1.5 \mathrm{~K}$ and are fluctuating at $4.6 \mathrm{~K}$.

\section{Stannides}

$\mathrm{Gd}_{3} \mathrm{Cu}_{4} \mathrm{Sn}_{4}$ [22] with the orthorhombic $\mathrm{Gd}_{3} \mathrm{Cu}_{4} \mathrm{Ge}_{4}$ type structure shows two successive magnetic ordering temperatures of 13 and $8.6 \mathrm{~K}$. The structure contains two crystallographically independent gadolinium sites $4 e$ and $2 d$ which can be resolved in the 
${ }^{155} \mathrm{Gd}$ spectra. The magnetic hyperfine fields at the two gadolinium nuclei follow $\mathrm{S}=$ $7 / 2$ Brillouin functions with saturated magnetic hyperfine fields of $26.8 \mathrm{~T}$ for the lower and $32.0 \mathrm{~T}$ for the higher magnetic ordering temperature.

The Gd $T_{\mathrm{x}} \mathrm{Sn}_{2}[T=\mathrm{Fe}(\mathrm{x}=0.17), \mathrm{Co}(\mathrm{x}=0.27), \mathrm{Ni}(\mathrm{x}=0.32), \mathrm{Cu}(\mathrm{x}=0.17)]$ stannides show significant defects on the transition metal positions [68]. Although one observes different VEC, the isomer shifts (Table 1) are very close and there is no clear trend either with $\mathrm{x}$ or VEC. The domain character of these partially filled structures is expressed by a slightly enhanced experimental line width. Nevertheless, full magnetic hyperfine field splitting is observed in the magnetically ordered state.

\section{Metal-Rich Gadolinium Compounds}

The metal-rich gadolinium compounds $\mathrm{GdCo}_{11} \mathrm{Ti}, \mathrm{GdFe}_{9} \mathrm{Ti}_{2}, \mathrm{GdNi}_{9} \mathrm{In}_{2}$, and $\mathrm{Gd}_{2} \mathrm{Cu}_{7} \mathrm{Al}_{10}$ [43] have quite complex crystal structures, however, these materials are quite interesting since at least $\mathrm{GdCo}_{11} \mathrm{Ti}\left(\mathrm{T}_{\mathrm{C}} \approx 100 \mathrm{~K}\right)$ and $\mathrm{GdFe}_{9} \mathrm{Ti}_{2}\left(\mathrm{~T}_{\mathrm{C}}=280 \mathrm{~K}\right)$ have high magnetic ordering temperatures. Among these compounds $\mathrm{GdNi}_{9} \mathrm{In}_{2}$ shows the largest quadrupole splitting parameter, while the $V_{\mathrm{zz}}$ component observed for $\mathrm{Gd}_{2} \mathrm{Cu}_{7} \mathrm{Al}_{10}$ is almost zero.

$\mathrm{GdFe}_{11} \mathrm{Ti}$ with $\mathrm{ThMn}_{12}$ type structure forms a hydride of composition $\mathrm{GdFe}_{11} \mathrm{TiH}_{1-\delta}$ [69]. The hydride formation strongly affects the electronic situation of the gadolinium atoms. First one observes an increase of the isomer shift, but also a significant increase of the quadrupole splitting parameter. Hydrogenation thus induces an increase of the second-order anisotropy term.

$\mathrm{Gd}_{2} \mathrm{Ni}_{2} \mathrm{Mg}$ [12] (tetragonal $\mathrm{Mo}_{2} \mathrm{~B}_{2} \mathrm{Fe}$ type) has one of the lowest isomer shift values $(0.13 \mathrm{~mm} / \mathrm{s})$ observed for intermetallic gadolinium compounds. The low site symmetry $(\mathrm{m} .2 \mathrm{~m})$ of the gadolinium atoms is reflected by a large quadrupole splitting parameter of $2.87 \mathrm{~mm} / \mathrm{s}$, even larger than the one observed for GdNiSn (Table 1) [41].

The Laves phase $\mathrm{GdMn}_{2}$ [70] has two different magnetic substructures arising from the gadolinium and manganese atoms. The manganese substructure is a frustrated threedimensional one. The magnetic ordering of the gadolinium atoms was monitored through ${ }^{155} \mathrm{Gd}$ Mössbauer spectroscopy, indicating that the gadolinium substructure remains ordered up to ca. $80 \mathrm{~K}$. Another interesting spillover of this study concerns the 
resolution of ${ }^{155} \mathrm{Gd}$ Mössbauer spectroscopy. A $2.5 \% \mathrm{Gd}_{2} \mathrm{O}_{3}$ impurity component was clearly detectable in the spectrum. GdMn 2 and also the isotypic Laves phases $\mathrm{GdFe}_{2}$ and $\mathrm{GdAl}_{2}$ have furthermore been studied under high-pressure conditions [71], underlining the pressure dependence of the hyperfine fields. $\mathrm{GdMn}_{2}$ [72] absorbs a distinct amount of hydrogen. The influence of hydrogen sorption on the ${ }^{155} \mathrm{Gd}$ spectra in the range $\mathrm{GdMn}_{2} \mathrm{H}_{\mathrm{x}}$ up to $\mathrm{x}=4.3$ has been studied. The hydrogenation drastically changes the isomer shift from 0.073 for $\mathrm{x}=0$ to 0.615 for $\mathrm{x}=4.3$ and one also observes a maximum of the magnetic hyperfine field for $\mathrm{x}=3.0$. For smaller hydrogen contents the spectra showed two spectral components, most likely due to domain formation.

\section{Germanides and Stannides with $\mathrm{HfFe}_{6} \mathrm{Ge}_{6}$ Type Structure}

First ${ }^{155} \mathrm{Gd}$ Mössbauer spectroscopic data on $\mathrm{GdMn}_{6} \mathrm{Ge}_{6}$ and $\mathrm{GdMn}_{6} \mathrm{Sn}_{6}$ have been reported by Mulder et al. [73]. Magnetic hyperfine field splitting with moderate values (Table 1) has been observed for both compounds. The quadrupolar splitting in the germanide is substantially larger than in the stannide. Later on field dependent studies have been performed for $\mathrm{GdMn}_{6} \mathrm{Sn}_{6}$ [74] in order to determine the sign of the hyperfine field. The Mössbauer spectroscopic data of the germanide are in agreement with a nuclear magnetic resonance analysis [75]. The gadolinium substructure of $\mathrm{GdFe}_{6} \mathrm{Ge}_{6}$ [76] shows the higher Curie temperature of $30.8 \mathrm{~K}$. This reference gives a complete overview on diverse intermetallic gadolinium compounds with $\mathrm{HfFe}_{6} \mathrm{Ge}_{6}$ type structure.

\section{Complex Aluminides}

The complex aluminide $\mathrm{GdPd}_{2} \mathrm{Al}_{3}$ [77] with $\mathrm{PrNi}_{2} \mathrm{Al}_{3}$ type structure shows a huge quadrupole splitting parameter of $5.64 \mathrm{~mm} / \mathrm{s}$ in the paramagnetic regime, emphasizing the strongly asymmetric charge distribution around the gadolinium nuclei. Full magnetic hyperfine field splitting occurs at 4.2 K. Slightly different Mössbauer parameters have been observed by Mulder et al. [78]. Although the $\mathrm{PrNi}_{2} \mathrm{Al}_{3}$ type contains only one crystallographic rare earth position, the spectra for this second $\mathrm{GdPd}_{2} \mathrm{Al}_{3}$ sample were fitted with two signals in $81: 19$ ratio with distinctly different $V_{z z}$ values and also substantially different hyperfine fields in the magnetically ordered regime. The origin of this discrepancy remains unclear. 
$\mathrm{GdNiAl}_{4}$ [79] shows two magnetic transitions at the Néel temperatures of 24.7 and $20.8 \mathrm{~K}$. The ${ }^{155} \mathrm{Gd}$ Mössbauer spectrum at $27 \mathrm{~K}$, slightly above the magnetic ordering temperature could be well reproduced with a single, quadrupole-split signal. Below the first magnetic ordering temperature the magnetic hyperfine field continuously increases with decreasing temperature and saturates at a value of $30 \mathrm{~T}$. Based on a point charge model estimation of the EFG, the gadolinium magnetization is aligned preferentially with either the $b$ - or the $c$-axis.

\section{Iron-Arsenide Superconductors}

From the large family of $\mathrm{ZrCuSiAs}$ type materials [80], GdFeAsO and the slightly overdoped superconductor $\mathrm{Gd}_{0.84} \mathrm{Th}_{0.16} \mathrm{FeAsO}$ [81] have recently been studied by ${ }^{57} \mathrm{Fe}$ and ${ }^{155} \mathrm{Gd}$ Mössbauer spectroscopy. The ${ }^{57} \mathrm{Fe}$ data clearly show that the supeconducting sample of $\mathrm{Gd}_{0.84} \mathrm{Th}_{0.16} \mathrm{FeAsO}$ shows no long-range magnetic ordering of the iron magnetic moments, while GdFeAsO shows full magnetic hyperfine field splitting in the magnetically ordered state. In contrast, the ${ }^{155} \mathrm{Gd}$ Mössbauer spectra show magnetic ortdering of the gadolinium moments in both compounds with an almost similar hyperfine field at $1.5 \mathrm{~K}$ (Table 1). The low site symmetry of the gadolinium atoms is reflected by substantial quadrupole splitting.

\section{Trends in the Isomer Shifts}

The various isomer shifts of the gadolinium intermetallics cover a broad range. They strongly depend on the nature of the elements coordinating the gadolinium atoms [82]. The values are relatively small if more transition metal atoms built up the coordination sphere (around $0.3 \mathrm{~mm} / \mathrm{s}$ ) and become larger for higher amounts of $s, p$ elements like aluminum (around $0.6 \mathrm{~mm} / \mathrm{s}$ ) or silicon / germanium (up to $0.8 \mathrm{~mm} / \mathrm{s}$ ).

In the last thirty years, besides some intermetallic compounds, also a variety of gadolinium containing oxides has been studied by ${ }^{155} \mathrm{Gd}$ Mössbauer spectroscopy. These results have been summarized in several papers on isomer shift scales [10, 83-85]. In total, the isomer shift scale for ${ }^{155} \mathrm{Gd}$ covers a range of more than $1 \mathrm{~mm} / \mathrm{s}$. Extreme compounds are an amorphous $\mathrm{Gd}_{80} \mathrm{Au}_{20}$ alloy with an isomer shift lower then $-0.2 \mathrm{~mm} / \mathrm{s}$ and $\mathrm{GdB}_{6}$ with an isomer shift of almost $0.9 \mathrm{~mm} / \mathrm{s}$ [10]. Selected compounds listed in Table 1 are plotted in an isomer shift scale in Figure 6. 
Examining the many data listed in Table 1 we can observe a clear trend. Especially for the series of $\operatorname{GdTX}$ and $\operatorname{Gd} T_{2} X_{2}$ compounds, the isomer shift increases with increasing VEC either within the $3 d, 4 d$, or $5 d$ row of transition metals, or with increasing VEC of the $p$ element. The manganese containing compounds deviate from this correlation, possibly due to a different electronic structure.

An increasing electron density at the gadolinium nuclei leads to a shift of the $\delta_{\text {IS }}$ values towards negative velocities. Over the whole range, for these intermetallic compounds we observe a considerable variation of the conduction electron character, with the largest $6 s$ contributions for the smallest isomer shift, and strong $5 d$ and / or $6 p$ predominance for the largest $\delta_{\text {IS }}$ values.

\section{Crystal Field Parameters derived from ${ }^{155}$ Gd Spectra}

The experimental determination of the quadrupole interaction at the Gd nuclei is of general interest for a deeper insight into the electronic properties of rare earth compounds. The trivalent gadolinium ion in the ${ }^{8} S_{7 / 2}$ electronic state with a spherical distribution of the $4 f$ electronic charge is insensitive to crystal field effects (CFE); hence the ${ }^{155} \mathrm{Gd}$ nucleus is a good probe for a lattice contribution to the electric field gradient.

The crystal electric field parameter (CEF) $A_{2}^{0}$ is commonly given by the relation [10, 86]:

$$
A_{2}^{0}=-V_{z z}\left(1-\sigma_{2}\right) /\left[4\left(1-\gamma_{\infty}\right)\right]
$$

Here, $\sigma_{2}$ is a screening coefficient estimated to be about 0.6 for any rare earth ion and $\gamma_{\infty}$ (and $\left(1-\gamma_{\infty}\right)$ is about 60) is the Sternheimer antishielding factor of the EFG produced by the lattice charges (i.e. the polarisation of the core electrons). Although the last relation has no fundamental basis from a theoretical point of view $[87,88]$ it was shown, however, that the proportionality between $V_{z z}$ and $A_{2}^{0}$ keeps rather well for individual rare earth series of different compounds $[10,43,44,49,51,78,86]$. The quantity $A_{2}^{0}$ is then a universal factor applicable to all isostructural compounds of rare earths, provided that the structural parameters do not significantly vary with the rare earth. $V_{z z}$ itself, which is an important solid state property, can be obtained easily from the quadrupole constant 
$\Delta E_{Q}\left({ }^{155} \mathrm{Gd}\right)$ using the following formula: $V_{z z}=2.2206 \cdot 10^{21} \Delta E_{Q}[\mathrm{~mm} / \mathrm{s}] \mathrm{V} / \mathrm{m}^{2}$. The next term of CEF, i.e. $A_{2}^{2}$ is directly related to the asymmetry parameter $\eta$ in the form:

$$
A_{2}^{2}=\eta A_{2}^{0}
$$

This term is always zero for a site with axial symmetry since then $\eta=0$.

\section{Hyperfine interactions and magnetic structures}

Generally, to get a complete description of the magnetic structure for a given solid, several experimental methods must be combined together. Among them there are macroscopic and microscopic techniques, such as magnetization and susceptibility measurements, neutron diffraction investigations, solid state NMR and of course Mössbauer spectroscopy. Hereafter, we would like to discuss the question what we can learn from ${ }^{155} \mathrm{Gd}$ Mössbauer spectroscopy concerning the spin configuration i.e. what are the spatial orientations of individual magnetic moments with respect to the crystallographic axes. First of all to answer this question, the knowledge of the direction of the EFG principal axis $V_{z z}$ should be known for all possible Gd sites in the structure what could be sometimes a serious task. Here, however, the symmetry conditions and the quality of the trial fits can be decisive in establishing mutual orientations of principal axes for the EFG tensor [21, 41].

Secondly, a magnetically split Gd spectrum has to be well resolved to allow its careful analysis and this second condition is usually not fulfilled in the case of ${ }^{155} \mathrm{Gd}$ Mössbauer spectroscopy. Obviously, this analysis is easier if Gd occupies only one crystallographic site with relatively high symmetry (for example tetragonal or hexagonal) and if the magnetically split spectrum can be fitted with a low number of magnetic components. However, the situation is not hopeless and there are many examples where this spectroscopy is successful in determining at least some of elements of magnetic ordering $[14,17,21,41,59]$ even for compounds with non-collinear magnetic structures. As a most spectacular example one can serve the tetragonal carbide $\mathrm{GdNi}_{2} \mathrm{~B}_{2} \mathrm{C}$ [59], where the application of ${ }^{155} \mathrm{Gd}$ Mössbauer spectroscopy and a sophisticated analysis of the recorded spectra at the magnetic regime revealed that below $T_{R}=14 \mathrm{~K}$ this compound orders in the bunched spiral-like structure with gadolinium magnetic moments rotating 
within the $b c$-plane while between $\mathrm{T}_{\mathrm{R}}$ and $\mathrm{T}_{\mathrm{N}}=20 \mathrm{~K}$ the existence of a sine-modulated type of structure was confirmed with the gadolinium magnetic moments perpendicular to the tetragonal $c$ axis.

As mentioned above, for the hexagonal antiferromagnetic stannide GdNiSn [41] two possible magnetic structures have been proposed for all temperatures below $\mathrm{T}_{\mathrm{N}}$. The first structure was described as a collinear one with the Gd magnetic moments lying in the $a b$-plane (or $c b$-plane) and the second as non-collinear structure with the Gd magnetic moments slightly deviated from the $c b$-plane. In the case of the antiferromagnetic carbide $\mathrm{GdRu}_{2} \mathrm{SiC}$ [21], magnetically split spectra between $\mathrm{T}_{\mathrm{N}}$ and $4.2 \mathrm{~K}$ can be well fitted with only one magnetic component but the spectrum recorded at $2.15 \mathrm{~K}$ can be effectively fitted with a characteristic distribution of magnetic hyperfine fields (Fig. 5). From the analysis of the obtained Mössbauer spectra it was shown that in the temperature region $4.2 \mathrm{~K} \leq \mathrm{T} \leq \mathrm{T}_{\mathrm{N}}$ a collinear magnetic structure is realized with the Gd magnetic moments ordered along the $a$-axis (being the $V_{z z}$ axis of the EFG tensor) or close to it, while at $\mathrm{T}=2.15 \mathrm{~K}$, a non-collinear magnetic structure appears resulting with the distribution of magnetic hyperfine fields. ${ }^{155} \mathrm{Gd}$ Mössbauer spectroscopic studies carried out for the ferromagnetic $\operatorname{GdTMg}(T=\mathrm{Pd}, \mathrm{Ag}, \mathrm{Pt})$ intermetallics [14] show that the derived $\theta$ angles are neither $0^{\circ}$ nor $90^{\circ}$ and these results point to a magnetic structure where the magnetic moments deviate from the crystallographic $c$ axis. In particular, if $V_{z z}$ is perpendicular to the $c$ axis then the magnetic moments would be confined within the basal $a b$-plane.

The presence of tin in ternary Gd stannides gives an exceptional opportunity to follow the magnetic phase transformations and magnetic interactions simultaneously at two different sites by means of two microscopic probes, namely the ${ }^{155} \mathrm{Gd}$ and ${ }^{119} \mathrm{Sn}$ isotopes. Such investigations showed, for example, that the magnetic structure of GdAgSn $[35,39]$ is not homogenous and the fact that the temperature dependence of the average magnetic hyperfine field $\left\langle H_{h f}\right\rangle$ at the $\mathrm{Sn}$ site does not follow an $\mathrm{S}_{7 / 2}$ Brillouin-function indicates more complex magnetic interactions, reflecting its more complex magnetic structure. In this context it is worth to note that tin is a diamagnetic atom and therefore ${ }^{119} \mathrm{Sn}$ Mössbauer spectroscopy is an ideal tool to study the so-called transferred hyper- 
fine field, i.e. the magnetic hyperfine field induced at the ${ }^{119} \mathrm{Sn}$ Mössbauer nucleus by the surrounding magnetic gadolinium atoms.

The magnetic hyperfine field at the gadolinium site $\boldsymbol{H}_{\boldsymbol{h} f}$ is usually presented in the form:

$$
\boldsymbol{H}_{h f}=\boldsymbol{H}_{C P}+\boldsymbol{H}_{C E}+\boldsymbol{H}_{D} \text { where } \boldsymbol{H}_{C E}=\boldsymbol{H}_{S}+\boldsymbol{H}_{T R} .
$$

The core-polarisation field $\boldsymbol{H}_{\boldsymbol{C P}}$ is caused by exchange interactions between $4 f$ and core electrons. Its value, $H_{C P}=(-340 \pm 20) \mathrm{kOe}[89,90]$ is assumed not to be dependent on the gadolinium environment in solids. $\boldsymbol{H}_{\boldsymbol{C} E}$ is the conduction electron contribution to the magnetic hyperfine field. The $\boldsymbol{H}_{\boldsymbol{S}}$ term is the self-polarisation field ascribed to polarisation of conduction electrons polarised by the given local $\mathrm{Gd}$ magnetic moment while $\boldsymbol{H}_{T \boldsymbol{R}}$ is the transferred field contribution due to the conduction electron polarisation by magnetic atoms in the surroundings. $\boldsymbol{H}_{\boldsymbol{D}}$ is the dipole field but its amplitude is usually small and therefore can be neglected in most cases. Hence, the conduction electron contribution $\boldsymbol{H}_{\boldsymbol{C}}$ can be estimated from the experimental result obtained for $\boldsymbol{H}_{\boldsymbol{h} f}$ as $H_{C E}=H_{h f}-H_{C P}$

\section{Orientations of rare earth magnetic moments as anticipated from ${ }^{155}$ Gd spectra}

Some useful information about the preferred arrangements of the magnetic rare earth moments can be derived from the analysis of the quadrupole interactions observed at the Gd nuclei.

The quantities $\Delta E_{Q}$ and $\eta$ obtained from ${ }^{155} \mathrm{Gd}$ Mössbauer spectroscopy can provide estimates for the quadrupolar terms $B_{2}^{0}$ and $B_{2}^{2}$ in the Stevens expansion $\Sigma B_{n}^{m} O_{n}^{m}$ of a coupling of the $4 f$ shell of rare earths with non-zero orbital angular momentum to the crystal field. Please note that these two quadrupolar terms $B_{2}^{m}$ are closely related to the previously defined $A_{2}^{m}$ CEF parameters by the expression [10]:

$$
B_{2}^{m}=Q_{4 f} A_{2}^{m}=\alpha_{J} \cdot<r^{2}>_{4 f} \cdot A_{2}^{m}
$$

where $Q_{4 f}=\alpha_{J} \cdot\left\langle r^{2}>_{4 f}\right.$ is the quadrupole moment of the $4 f$ state and here $\alpha_{J} \cdot$ is the Stevens factor while $\left\langle r^{2}\right\rangle_{4 f}$ is the mean squared radius of the $4 f$ wave function. 
Both $B_{2}^{m}$ parameters can be then expressed by the following formulæ: $B_{2}^{0}(K)=-$ $90.2 \cdot \alpha_{J} \cdot\left\langle r^{2}>_{4 f} \cdot \Delta E_{Q}{ }^{155} G d\right)$ and $B_{2}^{2}=\eta \cdot B_{2}^{0}$, where the mean squared radius of the $4 f$ wave function $\left\langle r^{2}\right\rangle_{4 f}$ for a given rare earth is expressed in atomic units and $\Delta E_{Q}$ in units of $\mathrm{mm} / \mathrm{s}$. Providing that $B_{2}^{0}$ is the leading term in the crystal field Hamiltonian, then when translated for other rare earth ions in the family of isostructural compounds, its sign gives information about the magnetocrystalline anisotropy, since then $H_{2}^{0}$ (CEF) $=B_{2}^{0}\left[3 \mathrm{~J}_{\mathrm{Z}}^{2}-\mathrm{J}(\mathrm{J}+1)\right]$. For a negative $B_{2}^{0}$ the ground state doublet is built up of states with a maximum absolute value of $\mathrm{J}_{\mathrm{Z}}$ which means that the magnetic moment is pointed in the direction of the $z$-quantization axis. In contrary, for positive values of $B_{2}^{0}$ only states with the possible smallest $\left|J_{z}\right|$ contribute to the electronic ground state and the magnetic moment is aligned in the basal plane $(\perp z)$. Such a procedure was satisfactorily applied in the case of compounds with tetragonal $[10,17,49,91]$ and hexagonal symmetry [74] giving a good agreement between predicted and experimentally observed directions of magnetic rare earth moments by neutron diffraction methods and (or) single crystal magnetizations studies. Obviously, this procedure is usually not applicable for lower symmetries where higher terms of the Stevens expansion have to be taken into account to get proper prediction concerning the easy direction or easy plane of magnetic rare earth moments.

This work was financially supported by the Deutsche Forschungsgemeinschaft through SPP 1166 Lanthanoidspezifische Funktionalitäten in Molekül und Material and by Poland's Committee for Scientific Research grant under contract No: 1 P03B 08428.

\section{References}

[1] A. Szytuła, J. Leciejewicz, Handbook of Crystal Structures and Magnetic Properties of Rare Earth Intermetallics, CRC Press, Boca Raton, 1994.

[2] K. P. Belov, Yu. V. Ergin, M. V., Moscow, Izv. Akad. Nauk SSSR, Ser. Fiz. 1966, 30, 975.

[3] S. N. Kaul, S. Srinath, Phys. Rev. B 2000, 62, 1114. 
[4] S. Yu. Dan'kov, A. M. Tishin, V. K. Pecharsky, K. A. Gschneidner, Jr., Phys. Rev. B 1998, 57, 3478.

[5] V. K. Pecharsky, K. A. Gschneidner, Jr., Phys. Rev. Lett. 1997, 78, 4494.

[6] M. Napoletano, F. Canepa, P. Manfrinetti, F. Merlo, J. Mater. Chem. 2000, 10, 1663.

[7] F. Canepa, M. L. Fornasini, F. Merlo, M. Napoletano, M. Pani, J. Alloys Compd. 2000, 312, 12 .

[8] S. J. Lee, K. J. Kim, Solid State Commun. 2001, 118, 269.

[9] F. Canepa, M. Napoletano, A. Palenzona, F. Merlo, S. Cirafici, J. Phys. D: Appl. Phys. 1999, 32, 2721.

[10] G. Czjzek, Mössbauer Spectroscopy of New Materials Containing Gadolinium, in G. J. Long, F. Grandjean (eds.), Mössbauer Spectroscopy applied to Magnetism and Materials Science, Modern Inorganic Chemistry Series (J. P. Fackler, series ed.), Plenum Press, New York, 1993, Chapter 9, pp. 373.

[11] R. Pöttgen, G. Kotzyba, E. A. Görlich, K. Łątka, R. Dronskowski, J. Solid State Chem. 1998, 141, 352.

[12] K. Łątka, R. Kmieć, A. W. Pacyna, R. Mishra, R. Pöttgen, Solid State Sci. 2001, 3,545 .

[13] R.-D. Hoffmann, R. Pöttgen, Th. Fickenscher, C. Felser, K. Łątka, R. Kmieć, Solid State Sci. 2002, 4, 609.

[14] K. Łątka, T. Tomkowicz, R. Kmieć, A. W. Pacyna, R. Mishra, T. Fickenscher, R.D. Hoffmann, R. Pöttgen, H. Piotrowski, J. Solid State Chem. 2002, 168, 331.

[15] K. Łątka, R. Kmieć, A. W. Pacyna, Th. Fickenscher, R.-D. Hoffmann, R. Pöttgen, Solid State Sci. 2004, 6, 301.

[16] K. Łątka, R. Kmieć, A. W. Pacyna, Th. Fickenscher, R.-D. Hoffmann, R. Pöttgen, J. Magn. Magn. Mater. 2004, 280, 90.

[17] K. Łątka, R. Kmieć, M. Rams, A. W. Pacyna, V. I. Zaremba, R. Pöttgen, Z. Naturforsch. 2004, 59b, 947.

[18] K. Łątka, R. Kmieć, R. Kruk, A. W. Pacyna, Th. Fickenscher, R.-D. Hoffmann, R. Pöttgen, J. Solid State Chem. 2005, 178, 2077.

[19] K. Łątka, R. Kmieć, A. W. Pacyna, J. Gurgul, V. I. Zaremba, R. Pöttgen, Solid State Sci. 2006, 8, 548.

[20] K. Łątka, M. Rams, R. Kmieć, A. W. Pacyna, V. I. Zaremba, U. Ch. Rodewald, R. Pöttgen, Solid State Sci. 2007, 9, 173.

[21] Th. Fickenscher, S. Rayaprol, J. von Appen, R. Dronskowski, R. Pöttgen, K. Łątka, J. Gurgul, Chem. Mater. 2008, 20, 1381.

[22] K. Łątka, A. W. Pacyna, R. Pöttgen, F. M. Schappacher, Acta Phys. Polon. A 2008, 114, 1501. 
[23] J. Gurgul, K. Łątka, A. W. Pacyna, M. Lukachuk, R. Pöttgen, Solid State Sci. 2009, $11,1680$.

[24] J. Silver, R. Withnall, Chem. Rev. 2004, 104, 2833.

[25] M. G. Kanatzidis, R. Pöttgen, W. Jeitschko, Angew. Chem. 2005, 117, 7156; Angew. Chem. Int. Ed. 2005, 44, 6996.

[26] C. L. Herzenberg, L. Meyer-Schützmeister, L. L. Lee, Jr., S. S. Hanna, Bull. Am. Phys. Soc. 1962, 7, 39.

[27] G. J. Long, T. E. Cranshaw, G. Longworth, Mössbauer Effect Ref. Data J. 1983, 6, 42.

[28] Y. Tanaka, D. B. Laubacher, R. M. Steffen, E. B. Shera, H. D. Wohlfahrt, M. V. Hoehn, Phys. Lett. B 1982, 108, 8.

[29] H. Armon, E. R. Bauminger, S. Ofer, Phys. Lett. B 1973, 43, 380.

[30] K. Tomala, G. Czjzek, J. Fink, H. Schmidt, Solid State Commun. 1977, 24, 857.

[31] J. G. Stevens, V. E. Stevens, Mössbauer Effect Data Index, IFI / Plenum, New York, 1978.

[32] J. W. C. de Vries, R. C. Thiel, K. H. J. Buschow, J. Phys. F: Met. Phys. 1985, 15, 2403.

[33] F. M. Mulder, R. C. Thiel, Europhys. Lett. 1994, 25, 657.

[34] F. M. Mulder, R. Coehoorn, R. C. Thiel, K. H. J. Buschow, Phys. Rev. B 1997, 56, 5786.

[35] E. A. Görlich, K. Łątka, R. Kmieć, W. Warkocki, Mol. Phys. Rep. 1998, 22, 35.

[36] D. Bialic, R. Kruk, R. Kmieć, K. Tomala, J. Alloys Compd. 1997, 257, 49.

[37] V. Ksenofontov, K. Kroth, S. Reiman, F. Casper, V. Jung, M. Takahashi, M. Takeda, C. Felser, Hyp. Int. 2006, 168, 1201.

[38] R.-D. Hoffmann, R. Pöttgen, Z. Kristallogr. 2001, 216, 127.

[39] K. Łątka, E. A. Görlich, W. Chajec, R. Kmieć, A. W. J. Pacyna, J. Alloys Compd. 1997, 262-263, 108.

[40] U. Ernet, R. Müllmann, B. D. Mosel, H. Eckert, R. Pöttgen, G. Kotzyba, J. Mater. Chem. 1997, 7, 255.

[41] R. Kmieć, Ż. Świątkowska, R. Kruk, K. Tomala, J. Magn. Magn. Mater. 2004, $271,326$.

[42] R. Mallik, E. V. Sampathkumaran, M. Strecker, G. Wortmann, Europhys. Lett. 1998, 41,315 .

[43] F. M. Mulder, R. C. Thiel, L. D. Tung, J. J. M. Franse, K. H. J. Buschow, J. Alloys Compd. 1998, 264, 43.

[44] F. M. Mulder, R. C. Thiel, K. H. J. Buschow, J. Alloys Compd. 1994, 205, 169.

[45] S. Rayaprol, C. P. Sebastian, R. Pöttgen, J. Solid State Chem. 2006, 179, 2041. 
[46] F. M. Mulder, R. C. Thiel, K. H. J. Buschow, J. Alloys Compd. 1994, 203, 97.

[47] B. Bielemeier, G. Wortmann, F. Casper, V. Ksenofontov, C. Felser, J. Alloys Compd. 2009, 480, 117.

[48] F. M. Mulder, R. C. Thiel, K. H. J. Buschow, J. Alloys Compd. 1997, 260, 32.

[49] F. M. Mulder, R. C. Thiel, K. H. J. Buschow, J. Alloys Compd. 1993, 202, 29.

[50] F. M. Mulder, R. C. Thiel, K. H. J. Buschow, J. Alloys Compd. 1995, 226, 100.

[51] F. M. Mulder, R. C. Thiel, K. H. J. Buschow, J. Alloys Compd. 1994, 210, 335.

[52] J. P. Sanchez, K. Tomala, K. Łątka, J. Magn. Magn. Mater. 1991, 99, 95.

[53] D. Kußmann, R. Pöttgen, U. Ch. Rodewald, C. Rosenhahn, B. D. Mosel, G. Kotzyba, B. Künnen, Z. Naturforsch. 1999, 54b, 1155.

[54] F. M. Mulder, R. C. Thiel, K. H. J. Buschow, J. Alloys Compd. 1994, 216, 95.

[55] M. Takeda, J, Wang, M. Takahashi, T. Shishido, A. Yoshikawa, A. Nakamura, J. Alloys Compd. 2006, 408-412, 371.

[56] S. Matsuo, H. Onodera, M. Kosaka, H. Kobayashi, M. Ohashi, H. Yamauchi, Y. Yamaguchi, J. Magn. Magn. Mater. 1996, 161, 255.

[57] H. Onodera, H. Amanai, S. Matsuo, M. Kosaka, H. Kobayashi, M. Ohashi, Y. Yamaguchi, Sci. Rep. RITU 1997, A45, 1.

[58] F. M. Mulder, J. H. V. J. Brabers, R. Coehoorn, R. C. Thiel, K. H. J. Buschow, F. R. de Boer, J. Alloys Compd. 1995, 217, 118.

[59] K. Tomala, J. P. Sanchez, P. Vulliet, P. C. Canfield, Z. Drzazga, A. Winiarska, Phys. Rev. B 1998, 58, 8534.

[60] J. C. P. Campoy, A. O. dos Santos, L. P. Cardoso, A. Paesano Jr, M. T. Raposo, J. D. Fabris, Hyp. Int. 2010, 195, 191.

[61] D. R. Noakes, G. K. Shenoy, D. Niarchos, A. M. Umarji, A. T. Aldred, Phys. Rev. B 1983, 27, 4317.

[62] W. Suski, H. Drulis, K. Wochowski, K. Tomala, R. Kmieć, Ya. M. Kalychak, V. I. Zaremba, T. Mydlarz, Z. Phys. B 1997, 102, 15.

[63] P. Wang, Z. M. Stadnik, J. Phys.: Condens. Matter 2007, 19, 346235.

[64] H. Nakamura, N. Kim, M. Shiga, R. Kmieć, K. Tomala, E. Ressouche, J. P. Sanchez, B. Malaman, J. Phys.: Condens. Matter 1999, 11, 1095.

[65] H. Nakamura, N. Kim, M. Shiga, R. Kmieć, K. Tomala, Hyp. Int. 1999, 120/121, 257.

[66] Z. M. Stadnik, K. Al-Qadi, P. Wang, J. Phys.: Condens. Matter 2007, 19, 326208.

[67] P. Wang, Z. M. Stadnik, K. Al-Qadi, J. Przewoźnik, J. Phys.: Condens. Matter 2009, 21, 436007.

[68] E. A. Görlich, K. Łątka, R. Kmieć, Z. Tomkowicz, W. Warkocki, Mol. Phys. Rep. 2000, 30, 59. 
[69] O. Isnard, P. Vulliet, J. P. Sanchez, D. Fruchart, J. Magn. Magn. Mater. 1998, $189,47$.

[70] K. Krop, Physica B 2002, 319, 9.

[71] M. Strecker, G. Wortmann, Hyp. Int. 1999, 120/121, 187.

[72] J. Żukrowski, M. Strecker, G. Wortmann, J. Przewoźnik, K. Krop, J. Alloys Compd. 1997, 261, 47.

[73] F. M. Mulder, R. C. Thiel, J. H. V. J. Brabers, F. R. de Boer, K. H. J. Buschow, J. Alloys Compd. 1993, 190, L29.

[74] B. Malaman, G. Venturini, R. Welter, J. P. Sanchez, P. Vulliet, E. Ressouche, J. Magn. Magn. Mater. 1999, 202, 519.

[75] P. Rösch, M. T. Kelemen, E. Dormann, G. Tomka, P. C. Riedi, J. Phys.: Condens. Matter 2000, 12, 1065.

[76] J. M. Cadogan, D. H. Ryan, J. D. Cashion, J. Phys.: Condens. Matter 2007, 19, 216204.

[77] E. Colineau, J. P. Sanchez, J. Rebizant, J. M. Winand, Solid State Commun. 1994, 92, 915 .

[78] F. M. Mulder, R. C. Thiel, K. H. J. Buschow, J. Alloys Compd. 1995, 223, 127.

[79] G. A. Stewart, W. D. Hutchison, A. V. J. Edge, K. Rupprecht, G. Wortmann, K. Nishimura, Y. Isikawa, J. Magn. Magn. Mater. 2005, 292, 72.

[80] R. Pöttgen, D. Johrendt, Z. Naturforsch. 2008, 63b, 1135.

[81] P. Wang, Z. M. Stadnik, C. Wang, G.-H. Cao, Z.-A. Xu, J. Phys.: Condens. Matter 2010, 22, 145701.

[82] J. W. C. de Vries, R. C. Thiel, K. H. J. Buschow, J. Phys. F 1985, 15, 1413.

[83] J. D. Cashion, D. B. Prowse, A. Vas, J. Phys. C 1973, 6, 2611.

[84] J. D. Cashion, M. A. Coulthard, D. B. Prowse, J. Phys. C 1974, 7, 3620.

[85] J. D. Cashion, M. A. Coulthard, D. B. Prowse, J. Phys. C 1975, 8, 1267.

[86] K. H. J. Buschow, F. M. Mulder, R. C. Thiel, J. Alloys Compd. 1998, 275-277, 498.

[87] R. Coehoorn, K. H. J. Buschow, M.W. Dirken, R. C. Thiel, Phys. Rev. B 1990, 42, 4645.

[88] K. H. J. Buschow, R. Coehoorn, F. M. Mulder, R. C. Thiel, J. Magn. Magn. Mater. 1993, 118, 347.

[89] R. E. Watson, A. J. Freeman, Hyperfine Interactions, A. J. Freeman, R. B. Frankel (eds.), Academic Press, New York, 1967, 53.

[90] R. E. Gegenwarth, J. I. Budnick, S. Skalski, J. H. Wernick, Phys. Rev. Lett. 1967, $18,9$.

[91] J. P. Sanchez, K. Tomala, A. Szytuła, Solid State Commun. 1991, 78, 419. 
Table 1. ${ }^{155} \mathrm{Gd}$ Mössbauer spectroscopic data of diverse intermetallic compounds: isomer shift, $\delta[\mathrm{mm} / \mathrm{s}]$; electric quadrupole splitting parameters, $\Delta E_{Q}^{\text {eff }}$ or $\Delta E_{Q}[\mathrm{~mm} / \mathrm{s}]$; magnetic hyperfine field, $H_{h f}[\mathrm{~T}]$. The temperature of the measurements is given in parentheses. Parameters without standard deviations had been constrained. In the case of two isomer shifts listed, the spectra were fitted with a superposition of two spectral components. The magnetic ordering temperatures $T_{\mathrm{M}}$ derived from susceptibility measurements (when available) are listed in a separate column.

\begin{tabular}{|c|c|c|c|c|c|c|}
\hline Compound & structure type & $\delta[\mathrm{mm} / \mathrm{s}] \Delta E_{Q}^{e f f}$ & or $\Delta E_{Q}[\mathrm{~mm} / \mathrm{s}]^{*}$ & $* \quad H_{h f}[\mathrm{~T}]$ & $T_{\mathrm{M}}[\mathrm{K}]$ & Reference \\
\hline \multicolumn{7}{|l|}{ aluminides } \\
\hline GdGaAl & $\mathrm{AlB}_{2}$ & 0.52 & -2.071 & 26.1 & 50 & [44] \\
\hline $\mathrm{GdGa}_{2} \mathrm{Al}_{2}(4.2 \mathrm{~K})$ & $\mathrm{ThCr}_{2} \mathrm{Si}_{2}$ & 0.58 & 1.306 & 29.2 & 42.4 & [51] \\
\hline \multirow{3}{*}{$\mathrm{GdCuAl}_{3}(4.2 \mathrm{~K})$} & $\mathrm{BaNiSn}_{3}$ & $0.57(51 \%)$ & 3.828 & 18.5 & 10.0 & {$[54]$} \\
\hline & & $0.57(37 \%)$ & 2.702 & 28.7 & & [54] \\
\hline & & $0.57(12 \%)$ & 0.811 & 14.5 & & [54] \\
\hline $\mathrm{GdPd}_{2} \mathrm{Al}_{3}(20 \mathrm{~K})$ & $\mathrm{PrNi}_{2} \mathrm{Al}_{3}$ & $0.482(6)$ & $5.64(3)$ & - & & [77] \\
\hline $\mathrm{GdPd}_{2} \mathrm{Al}_{3}(4.2 \mathrm{~K})$ & $\mathrm{PrNi}_{2} \mathrm{Al}_{3}$ & $0.482(11)$ & 5.64 & 27.1(3) & & [77] \\
\hline $\mathrm{GdNiAl}_{4}(4.2 \mathrm{~K})$ & $\mathrm{YNiAl}_{4}$ & $0.528(2)$ & $3.594(9)$ & $30^{\text {saturation field }}$ & 24.7 & [79] \\
\hline \multicolumn{7}{|l|}{ gallides } \\
\hline $\mathrm{GdNiGa}_{3}(4.2 \mathrm{~K})$ & $\mathrm{BaNiSn}_{3}$ & 0.59 & 2.792 & 28.5 & 14.5 & [54] \\
\hline $\mathrm{GdCuGa}_{3}(4.2 \mathrm{~K})$ & $\mathrm{BaNiSn}_{3}$ & 0.62 & 3.422 & 28.7 & 10.1 & [54] \\
\hline \multicolumn{7}{|l|}{ indium compounds } \\
\hline GdAuIn $(4.2 \mathrm{~K})$ & $\mathrm{ZrNiAl}$ & $0.355(4)$ & $-2.828(16)$ & $18.4(2)$ & 12.5 & [11] \\
\hline $\mathrm{GdAu}_{0.44} \mathrm{In}_{1.56}$ & $\mathrm{NdPtSb}$ & $0.452(10)$ & $-3.368(16)$ & $19.8(1)$ & 21.0 & [11] \\
\hline \multirow{2}{*}{$\mathrm{Gd}_{4} \mathrm{Pd}_{10} \mathrm{In}_{21}(20 \mathrm{~K})$} & $\mathrm{Ho}_{4} \mathrm{Ni}_{10} \mathrm{Ga}_{21}$ & $0.56(2)$ & $1.98(1)$ & - & 14.2 & {$[20]$} \\
\hline & & $0.57(1)$ & $4.48(1)$ & - & & \\
\hline LT-GdNiIn $_{2}(78 \mathrm{~K})$ & $\mathrm{MgCuAl}_{2}$ & $0.47(1)$ & $4.16(5)$ & - & 60.5 & [19] \\
\hline LT-GdNiIn $(4.2 \mathrm{~K})$ & $\mathrm{MgCuAl}_{2}$ & $0.46(1)$ & 4.16 & $25.4(3)$ & & [19] \\
\hline $\mathrm{GdRhIn}_{5}(47 \mathrm{~K})$ & $\mathrm{HoCoGa}_{5}$ & $0.657(2)$ & $0.684(8)$ & - & 41.0 & [17] \\
\hline $\mathrm{GdRhIn}_{5}(4.2 \mathrm{~K})$ & $\mathrm{HoCoGa}_{5}$ & $0.660(2)$ & -0.684 & $23.34(7)$ & & {$[17]$} \\
\hline $\mathrm{GdCu}_{5.1} \mathrm{In}_{6.9}(4.2 \mathrm{~K})$ & $\mathrm{ThMn}_{12}$ & $0.590(6)$ & $0.60(12)$ & $25.0(3)$ & 13.4 & {$[62]$} \\
\hline $\mathrm{GdCu}_{2} \mathrm{In}(1.5 \mathrm{~K})$ & $\mathrm{MnCu}_{2} \mathrm{Al}$ & $0.414(5)$ & - & $22.7(3)$ & 9.6 & {$[63]$} \\
\hline $\mathrm{GdPt}_{4} \mathrm{In}(30 \mathrm{~K})$ & $\mathrm{MgCu}_{4} \mathrm{Sn}$ & $0.34(1)$ & $1.28(2)$ & - & 21.9 & [23] \\
\hline $\mathrm{GdPt}_{4} \operatorname{In}(4.2 \mathrm{~K})$ & $\mathrm{MgCu}_{4} \mathrm{Sn}$ & $0.32(1)$ & $\pm 1.28(4)$ & $16.5(2)$ & & {$[23]$} \\
\hline $\begin{array}{l}\mathrm{Gd}_{14} \mathrm{Ag}_{50} \mathrm{In}_{36}(1.5 \mathrm{~K}) \\
\text { carbides }\end{array}$ & quasicrystal & $0.52(2)$ & $-2.4(1)$ & 12(1) & 4.25 & {$[66,67]$} \\
\hline $\mathrm{GdNiC}_{2}(4.2 \mathrm{~K})$ & $\mathrm{CeNiC}_{2}$ & $0.66(3)$ & $-1.43(5)$ & $34.0(5)$ & 20.0 & {$[56,57]$} \\
\hline $\mathrm{GdCoC}_{2}(4.2 \mathrm{~K})$ & $\mathrm{CeCoC}_{2}$ & $0.61(3)$ & $2.57(5)$ & $25.7(5)$ & 15.6 & {$[56,57]$} \\
\hline $\mathrm{GdRu}_{2} \mathrm{SiC}(4.2 \mathrm{~K})$ & $\mathrm{DyFe}_{2} \mathrm{SiC}$ & $0.516(3)$ & -1.03 & $27.3(1)$ & 10 & [21] \\
\hline $\mathrm{GdCo}_{2} \mathrm{~B}_{2} \mathrm{C}(4.2 \mathrm{~K})$ & $\mathrm{LuNi}_{2} \mathrm{~B}_{2} \mathrm{C}$ & 0.50 & 3.332 & -45.6 & & [58] \\
\hline $\mathrm{GdNi}_{2} \mathrm{~B}_{2} \mathrm{C}(4.2 \mathrm{~K})$ & $\mathrm{LuNi}_{2} \mathrm{~B}_{2} \mathrm{C}$ & 0.56 & 5.44 & -27.9 & & {$[58]$} \\
\hline $\mathrm{GdNi}_{2} \mathrm{~B}_{2} \mathrm{C}(4.2 \mathrm{~K})$ & $\mathrm{LuNi}_{2} \mathrm{~B}_{2} \mathrm{C}$ & 0.54 & 5.38 & $* *$ & & [59] \\
\hline \multicolumn{7}{|l|}{ silicides } \\
\hline GdMnSi (4.2 K) & $\mathrm{CeFeSi}$ & 0.37 & -1.441 & 22.6 & & {$[48]$} \\
\hline $\mathrm{GdFeSi}(4.2 \mathrm{~K})$ & $\mathrm{CeFeSi}$ & 0.35 & -0.811 & 24.0 & & [48] \\
\hline $\mathrm{Gd}_{2} \mathrm{Fe}_{3} \mathrm{Si}_{5}(4.2 \mathrm{~K})$ & $\mathrm{U}_{2} \mathrm{Mn}_{3} \mathrm{Si}_{5}$ & $0.54(3)$ & $-3.7(1)$ & $26(3)$ & 8.6 & [61] \\
\hline $\operatorname{GdCoSi}(4.2 \mathrm{~K})$ & $\mathrm{CeFeSi}$ & 0.35 & 2.207 & 28.5 & & {$[48]$} \\
\hline $\mathrm{GdCuSi}(4.2 \mathrm{~K})$ & $\mathrm{AlB}_{2}$ & 0.45 & -1.441 & 30.5 & 14 & [44] \\
\hline \multirow[t]{2}{*}{$\mathrm{Gd}_{2} \mathrm{RhSi}_{3}(0.5 \mathrm{~K})$} & $\mathrm{Er}_{2} \mathrm{RhSi}_{3}$ & $0.44(70 \%)$ & 4.728 & 24.0 & 14 & [43] \\
\hline & & $0.63(30 \%)$ & 1.171 & 28.2 & & \\
\hline \multirow[t]{2}{*}{$\mathrm{Gd}_{5} \mathrm{Ge}_{2} \mathrm{Si}_{1.54} \mathrm{Sn}_{0.46}(4.2 \mathrm{~K})$} & $\mathrm{Gd}_{5} \mathrm{Si}_{2} \mathrm{Ge}_{2}$ & $0.51(87 \%)$ & 0.87 & - & & {$[60]$} \\
\hline & & $0.61(13 \%)$ & 3.47 & - & & \\
\hline \multirow[t]{2}{*}{$\mathrm{Gd}_{5} \mathrm{Ge}_{2} \mathrm{Si}_{1.20} \mathrm{Sn}_{0.80}(4.2 \mathrm{~K})$} & $\mathrm{Gd}_{5} \mathrm{Si}_{2} \mathrm{Ge}_{2}$ & $0.34(79 \%)$ & 0.53 & - & & {$[60]$} \\
\hline & & $0.48(21 \%)$ & 1.99 & - & & \\
\hline $\mathrm{GdCoSi}_{3}(4.2 \mathrm{~K})$ & $\mathrm{BaNiSn}_{3}$ & 0.57 & 1.756 & 25.6 & 9.6 & [54] \\
\hline $\mathrm{GdIrSi}_{3}(4.2 \mathrm{~K})$ & $\mathrm{BaNiSn}_{3}$ & $0.640(12)$ & $2.03(18)$ & $28.0(6)$ & 15.5 & {$[52]$} \\
\hline
\end{tabular}




\begin{tabular}{|c|c|c|c|c|c|c|}
\hline germanides & & & & & & \\
\hline $\mathrm{GdAl}_{2} \mathrm{Ge}_{2}$ & $\mathrm{CaAl}_{2} \mathrm{Si}_{2}$ & 0.57 & 0 & 26.9 & 19.7 & [43] \\
\hline $\mathrm{GdCuGe} 4.2 \mathrm{~K})$ & $\mathrm{NdPtSb}$ & 0.47 & -1.261 & 28.2 & 19.0 & [44] \\
\hline $\operatorname{GdAgGe}(4.2 \mathrm{~K})$ & $\mathrm{ZrNiAl}$ & $0.443(4)$ & $-3.364(12)$ & $26.8(2)$ & 13.0 & [11] \\
\hline GdAuGe $(4.2 \mathrm{~K})$ & $\mathrm{NdPtSb}$ & $0.484(3)$ & $-0.44(16)$ & $26.6(1)$ & 16.9 & [11] \\
\hline $\mathrm{GdMn}_{2} \mathrm{Ge}_{2}(4.2 \mathrm{~K})$ & $\mathrm{ThCr}_{2} \mathrm{Si}_{2}$ & 0.56 & -2.387 & 16.6 & 365 & [49] \\
\hline $\mathrm{GdFe}_{2} \mathrm{Ge}_{2}(4.2 \mathrm{~K})$ & $\mathrm{ThCr}_{2} \mathrm{Si}_{2}$ & 0.54 & -3.197 & 29.6 & 10 & [49] \\
\hline $\mathrm{GdCo}_{2} \mathrm{Ge} 2(4.2 \mathrm{~K})$ & $\mathrm{ThCr}_{2} \mathrm{Si}_{2}$ & 0.53 & -2.116 & 31.8 & 40 & [49] \\
\hline $\mathrm{GdNi}_{2} \mathrm{Ge}_{2}(4.2 \mathrm{~K})$ & $\mathrm{ThCr}_{2} \mathrm{Si}_{2}$ & 0.58 & -0.675 & 31.9 & 22 & [49] \\
\hline $\mathrm{GdCu}_{2} \mathrm{Ge}_{2}(4.2 \mathrm{~K})$ & $\mathrm{ThCr}_{2} \mathrm{Si}_{2}$ & 0.63 & 1.261 & 26.6 & 12.5 & [49] \\
\hline $\mathrm{GdRu}_{2} \mathrm{Ge}_{2}(4.2 \mathrm{~K})$ & $\mathrm{ThCr}_{2} \mathrm{Si}_{2}$ & 0.46 & -8.151 & 28.6 & 32 & [49] \\
\hline $\mathrm{GdRh}_{2} \mathrm{Ge}_{2}(4.2 \mathrm{~K})$ & $\mathrm{ThCr}_{2} \mathrm{Si}_{2}$ & 0.55 & -3.152 & 31.9 & 93 & [49] \\
\hline $\mathrm{GdPd}_{2} \mathrm{Ge}_{2}(4.2 \mathrm{~K})$ & $\mathrm{ThCr}_{2} \mathrm{Si}_{2}$ & 0.58 & 0.270 & 27.5 & 9.0 & [49] \\
\hline $\mathrm{GdAg}_{2} \mathrm{Ge}_{2}(4.2 \mathrm{~K})$ & $\mathrm{ThCr}_{2} \mathrm{Si}_{2}$ & 0.68 & 1.891 & 24.6 & & [49] \\
\hline $\mathrm{GdMn}_{6} \mathrm{Ge}_{6}(4.2 \mathrm{~K})$ & $\mathrm{HfFe}_{6} \mathrm{Ge}_{6}$ & $0.49(1)$ & $-1.53(13)$ & $7.4(5)$ & 485 & [73] \\
\hline $\begin{array}{l}\mathrm{GdFe}_{6} \mathrm{Ge}_{6}(5 \mathrm{~K}) \\
\text { stannides }\end{array}$ & $\mathrm{HfFe}_{6} \mathrm{Ge}_{6}$ & $0.482(4)$ & $-0.261(95)$ & $25.6(1)$ & & [76] \\
\hline GdNiSn $(4.2 \mathrm{~K})$ & TiNiSi & $0.405(6)$ & 1.81 & $21.3(2)$ & & [41] \\
\hline GdCuSn $(35 \mathrm{~K})$ & $\mathrm{NdPtSb}$ & $0.45(1)$ & $1.62(1)$ & - & & [36] \\
\hline $\mathrm{GdCuSn}(4.2 \mathrm{~K})$ & $\mathrm{NdPtSb}$ & $0.45(1)$ & $1.63(1)$ & $21.4(3)$ & & [36] \\
\hline GdRhSn $(4.2 \mathrm{~K})$ & $\mathrm{ZrNiAl}$ & $0.351(3)$ & -2.642 & 20.8 & 16.0 & [18] \\
\hline $\operatorname{GdAgSn}(4.2 \mathrm{~K})$ & $\mathrm{NdPtSb}$ & - & - & 24.5 & 34.3 & [35] \\
\hline GdAuSn $(35 \mathrm{~K})$ & $\mathrm{NdPtSb}$ & $0.48(1)$ & $0.37(10)$ & - & 22.9 & [36] \\
\hline GdAuSn $(4.2 \mathrm{~K})$ & $\mathrm{NdPtSb}$ & $0.47(1)$ & 0.37 & 23.1(3) & & [36] \\
\hline $\mathrm{Gd}_{3} \mathrm{Cu}_{4} \mathrm{Sn}_{4}(20 \mathrm{~K})$ & $\mathrm{Gd}_{3} \mathrm{Cu}_{4} \mathrm{Ge}_{4}$ & $0.55(2)$ & $2.301(1)$ & - & 13 & [22] \\
\hline & & $0.53(1)$ & $3.584(1)$ & - & & \\
\hline $\mathrm{GdFe}_{0.17} \mathrm{Sn}_{2}(4.2 \mathrm{~K})$ & $\mathrm{CeNiSi}_{2}$ & $0.558(3)$ & $-1.72(4)$ & $25.3(2)$ & & [68] \\
\hline $\mathrm{GdCo}_{0.27} \mathrm{Sn}_{2}(4.2 \mathrm{~K})$ & $\mathrm{CeNiSi}_{2}$ & $0.580(3)$ & $-1.41(4)$ & $24.7(2)$ & & [68] \\
\hline $\mathrm{GdNi}_{0.32} \mathrm{Sn}_{2}(4.2 \mathrm{~K})$ & $\mathrm{CeNiSi}_{2}$ & $0.588(3)$ & $-1.28(4)$ & $24.7(2)$ & & {$[68]$} \\
\hline $\mathrm{GdCu}_{0.17} \mathrm{Sn}_{2}(4.2 \mathrm{~K})$ & $\mathrm{CeNiSi}_{2}$ & $0.569(4)$ & $-1.84(4)$ & $27.9(2)$ & & [68] \\
\hline $\mathrm{GdMn}_{6} \mathrm{Sn}_{6}(4.2 \mathrm{~K})$ & $\mathrm{HfFe}_{6} \mathrm{Ge}_{6}$ & $0.55(1)$ & $-0.90(13)$ & $11.6(9)$ & & [73] \\
\hline $\mathrm{GdMn}_{6} \mathrm{Sn}_{6}(4.2 \mathrm{~K})$ & $\mathrm{HfFe}_{6} \mathrm{Ge}_{6}$ & $0.573(5)(0 \mathrm{~T})$ & $0.89(3)$ & $4.0(5)$ & & [74] \\
\hline & & $0.57(1)(8 \mathrm{~T})$ & $1.00(6)$ & $-12.8(4)$ & & \\
\hline arsenides & & & & & & \\
\hline GdFeAsO $(1.5 \mathrm{~K})$ & $\mathrm{ZrCuSiAs}$ & $0.468(11)$ & $-3.40(15)$ & $27.8(8)$ & 4.1 & [80] \\
\hline $\begin{array}{l}\mathrm{Gd}_{0.84} \mathrm{Th}_{0.16} \mathrm{Fe} \mathrm{AsO} \\
\text { antimonides }\end{array}$ & $\mathrm{ZrCuSiAs}$ & $0.491(12)$ & $-3.0(2)$ & $24.6(11)$ & & [80] \\
\hline GdNiSb & $\mathrm{MgAgAs}$ & $0.484(4)$ & _- & 25 & & [47] \\
\hline GdNiSb $(1.85 \mathrm{~K})$ & $\mathrm{AlB}_{2}$ & $0.460(6)$ & -4.818 & 12 & & [47] \\
\hline GdPdSb $(1.85 \mathrm{~K})$ & NdPtSb & $0.468(4)$ & 0.743 & 25.5 & & [47] \\
\hline $\mathrm{GdCu}_{2} \mathrm{Sb}_{2}(13 \mathrm{~K})$ & $\mathrm{ThCr}_{2} \mathrm{Si}_{2}$ & 0.62 & 1.081 & 4.5 & 15.8 & [51] \\
\hline $\mathrm{GdCu}_{2} \mathrm{Sb}_{2}(4.2 \mathrm{~K})$ & $\mathrm{ThCr}_{2} \mathrm{Si}_{2}$ & 0.62 & 1.306 & 27.3 & & [51] \\
\hline $\mathrm{GdNi}_{2} \mathrm{Sb}_{2}(25 \mathrm{~K})$ & $\mathrm{ThCr}_{2} \mathrm{Si}_{2}$ & 0.60 & -1.396 & 4.0 & 6.5 & [51] \\
\hline $\begin{array}{l}\mathrm{GdNi}_{2} \mathrm{Sb}_{2}(1.5 \mathrm{~K}) \\
\text { magnesium compounds }\end{array}$ & $\mathrm{ThCr}_{2} \mathrm{Si}_{2}$ & 0.60 & -1.621 & 28.9 & & [51] \\
\hline $\operatorname{GdPdMg}(4.2 \mathrm{~K})$ & $\mathrm{ZrNiAl}$ & $0.192(7)$ & $1.93(4)$ & $21.2(2)$ & 95.7 & [14] \\
\hline $\operatorname{GdAgMg}(4.2 \mathrm{~K})$ & $\mathrm{ZrNiAl}$ & $0.272(3)$ & $2.11(2)$ & 21.4(1) & 39.3 & [14] \\
\hline $\operatorname{GdPtMg}(4.2 \mathrm{~K})$ & $\mathrm{ZrNiAl}$ & $0.190(4)$ & $2.36(2)$ & $18.8(2)$ & 97.6 & [14] \\
\hline GdAuMg $(4.2 \mathrm{~K})$ & $\mathrm{ZrNiAl}$ & $0.294(8)$ & $2.58(3)$ & $16.5(5)$ & 81.1 & [15] \\
\hline $\mathrm{GdPdCd}(4.2 \mathrm{~K})$ & $\mathrm{ZrNiAl}$ & $0.247(2)$ & $1.14(3)$ & $23.1(1)$ & 62.5 & {$[13]$} \\
\hline GdAuCd $(4.2 \mathrm{~K})$ & $\mathrm{ZrNiAl}$ & $0.337(4)$ & $1.97(3)$ & $19.9(2.2)$ & 66.5 & [16] \\
\hline metal-rich compoun & & & & & & \\
\hline $\mathrm{GdCo}_{11} \mathrm{Ti}(4.2 \mathrm{~K})$ & $\mathrm{ThMn}_{12}$ & 0.23 & -1.036 & 13.5 & 1000 & [43] \\
\hline $\mathrm{GdFe}_{9} \mathrm{Ti}_{2}(4.2 \mathrm{~K})$ & $\mathrm{CeMn}_{6} \mathrm{Ni}_{5}$ & 0.22 & 1.171 & 14.7 & 280 & [43] \\
\hline $\mathrm{GdNi}_{9} \mathrm{In}_{2}(4.2)$ & $\mathrm{CeMn}_{6} \mathrm{Ni}_{5}$ & 0.35 & \pm 3.107 & 0 & $<2$ & [43] \\
\hline
\end{tabular}




\begin{tabular}{lcccccc}
$\mathrm{Gd}_{2} \mathrm{Cu}_{7} \mathrm{Al}_{10}(4.2)$ & $\mathrm{Th}_{2} \mathrm{Zn}_{17}$ & 0.56 & 0 & 26.1 & 12 & {$[43]$} \\
$\mathrm{GdFe}_{11} \mathrm{Ti}(4.2 \mathrm{~K})$ & $\mathrm{ThMn}_{12}$ & $0.26(1)$ & $0.26(5)$ & $17.5(2)$ & 621 & {$[69]$} \\
$\mathrm{GdFe}_{11} \mathrm{TiH}_{1-\delta}(4.2 \mathrm{~K})$ & $\mathrm{ThMn}_{12}$ & $0.30(1)$ & $0.40(5)$ & $18.4(2)$ & 652 & {$[69]$} \\
$\mathrm{Gd}_{2} \mathrm{Ni}_{2} \mathrm{Mg}(4.2 \mathrm{~K})$ & $\mathrm{Mo}_{2} \mathrm{~B}_{2} \mathrm{Fe}$ & $0.13(1)$ & $2.87(3)$ & $14.6(2)$ & 49.0 & {$[12]$} \\
\hline * Please note that presented here quadrupole spiltting constants $(\mathrm{QSC}) \Delta E_{Q}^{\text {eff }}=\left|e Q_{g} V_{z z}\right| \cdot\left(1+\eta^{2} / 3\right)^{1 / 2}$ or $\Delta E_{Q}$ are
\end{tabular}
defined in a uniform way as $\Delta E_{Q}^{e f f}=\left|e Q_{g} V_{z z}\right| \cdot\left(1+\eta^{2} / 3\right)^{1 / 2}$ and $\Delta E_{Q}=e Q_{g} V_{z z}$. The lack of an error at a given QSC means that its absolute value was kept constant during the fitting procedure to that obtained at the paramagnetic state while its sign was varied to get the best fit to the spectra recorded below a magnetic transition temperature.

\pm - means that the sign of QSC was undetermined.

** The analysis of the spectra obtained below $\mathrm{T}=14 \mathrm{~K}$ leads to the complex bunched spiral-like magnetic structure with the different magnetic hyperfine fields at the $n$th gadolinium site. For details see [59]. 


\section{Figure Captions}

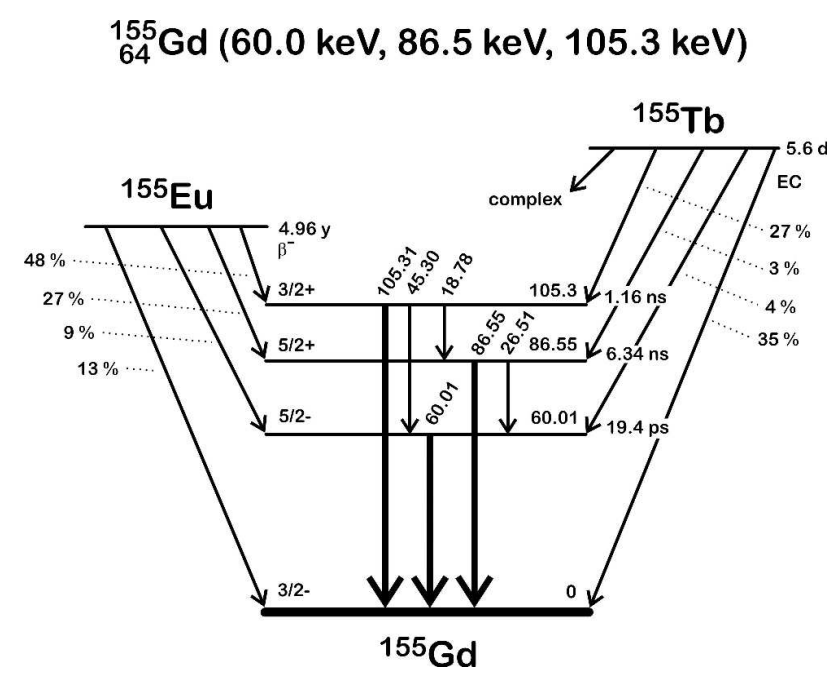

Fig. $1 \gamma$-ray transition scheme for ${ }^{155} \mathrm{Gd}$, redrawn from [31].

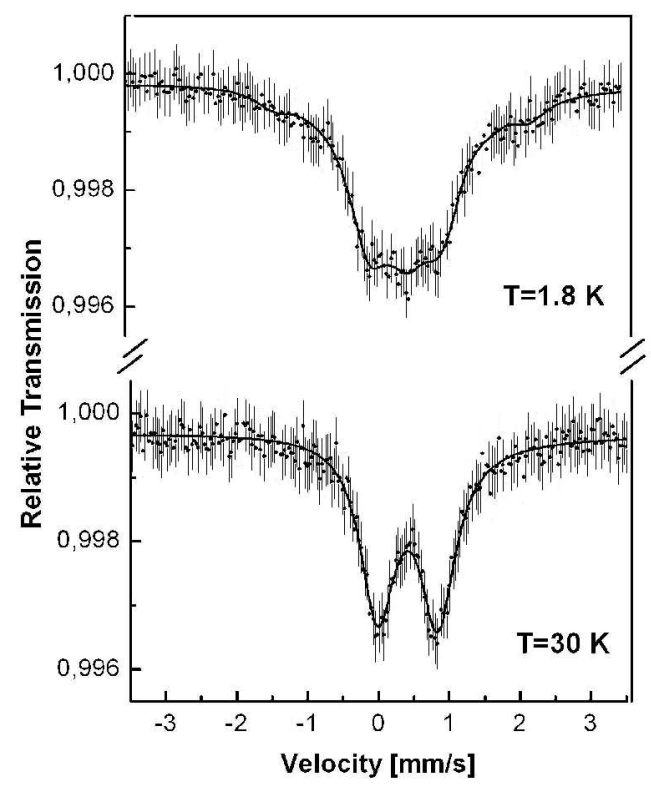

Fig. $2{ }^{155} \mathrm{Gd}$ Mössbauer spectra of $\mathrm{Gd}_{0.1} \mathrm{~Tb}_{0.9} \mathrm{NiSn}$ taken above and below the Néel temperature. Reproduced from [41] with permission of Elsevier. 


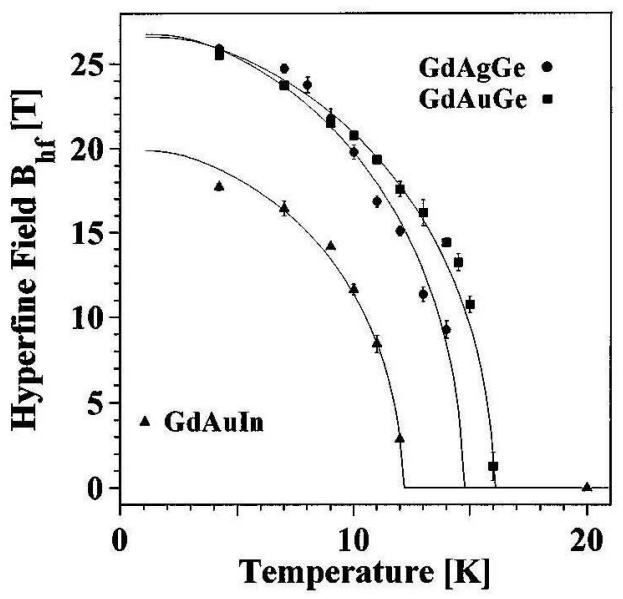

Fig. 3 Temperature dependence of the internal magnetic hyperfine fields of GdAgGe, GdAuGe, and GdAuIn. Reproduced from [11] with permission of Elsevier.

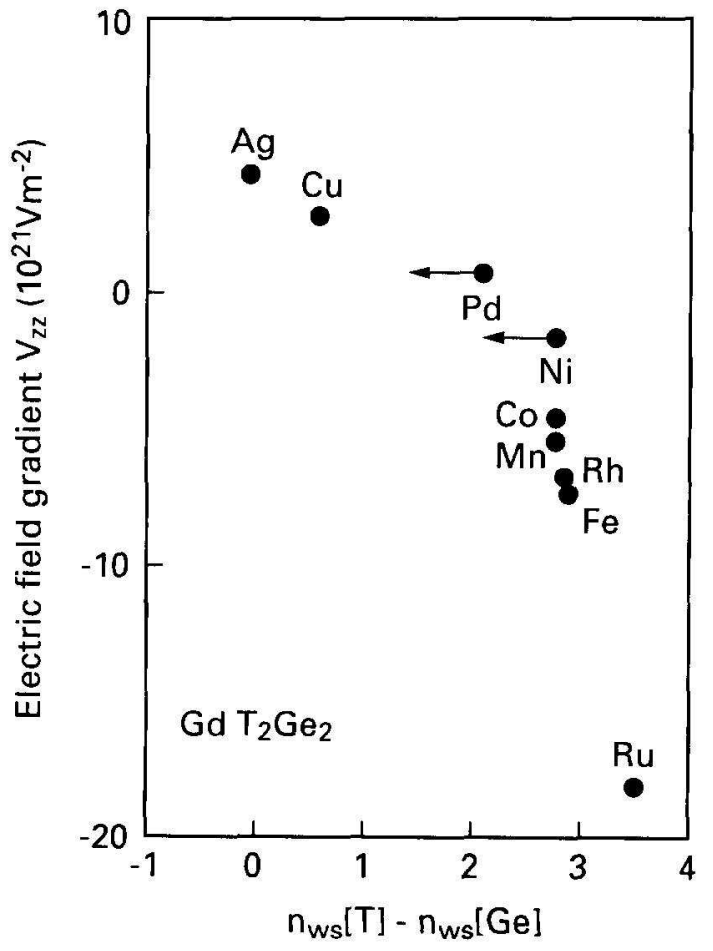

Fig. 4 Dependence of experimentally derived $V_{z z}$ values of the germanides $\mathrm{Gd}_{2} \mathrm{Ge}_{2}$ on the difference of the electron density $\mathrm{n}_{\mathrm{WS}}$ at the edge of the atomic shell of the $T$ and Ge atoms using Miedema's model. Reproduced from [49] with permission of Elsevier. 


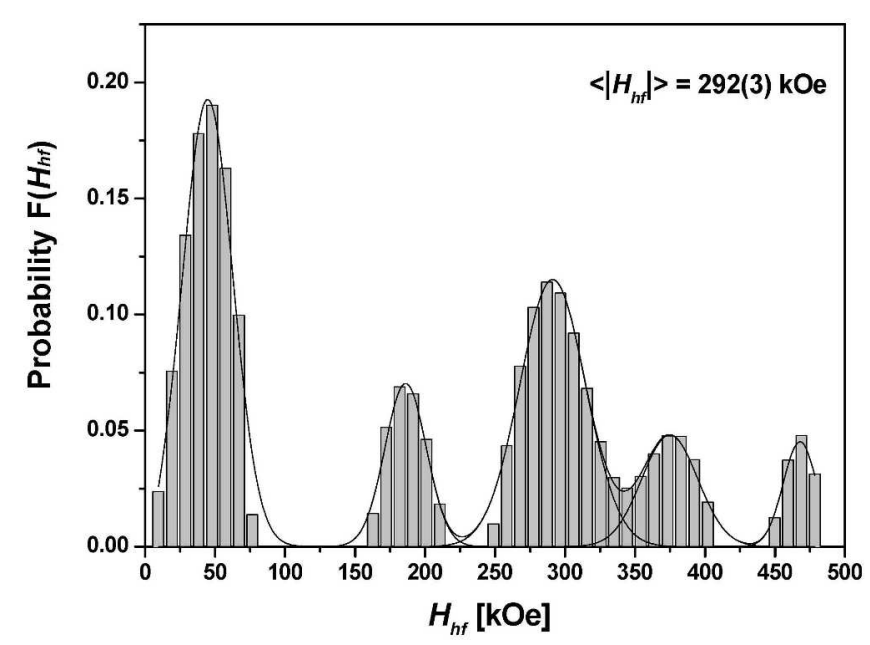

Fig. 5 Field distribution function $\mathrm{F}\left(H_{h f}\right)$ obtained for the ${ }^{155} \mathrm{Gd}$ spectrum of $\mathrm{GdRu}_{2} \mathrm{SiC}$ recorded at $T=2.15 \mathrm{~K}$. Solid lines denote Gaussian profiles fitted to the distribution. Reproduced from [21] with permission of ACS. Please note that the last profile above $425 \mathrm{kOe}$ can be an artefact of the fitting procedure.

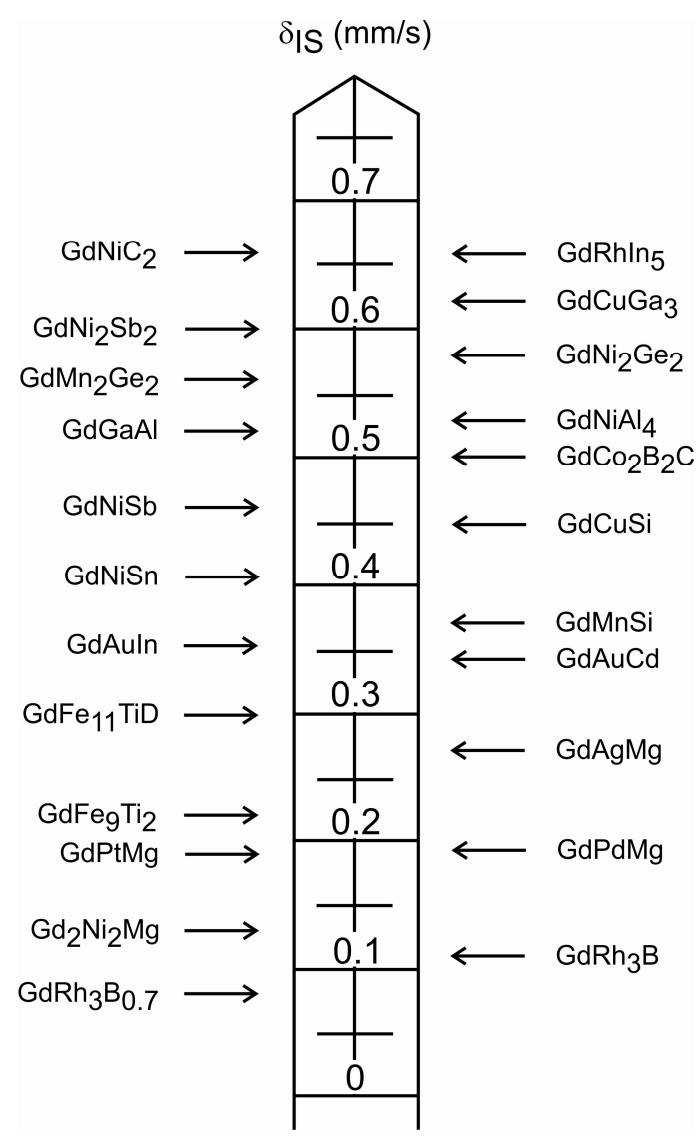

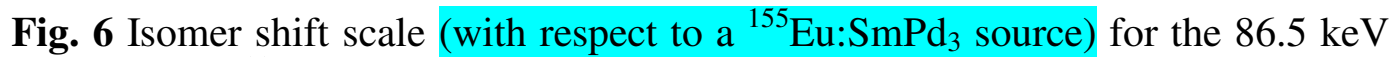
transition of ${ }^{155} \mathrm{Gd}$ for selected compounds of Table 1. For details see text. 